\title{
THE EVALUATION OF \\ FEDERAL FABRICS-FIBERS \\ ELECTROCHEMICAL CAPACITORS
}

\author{
R. B. Wright \\ T. C. Murphy
}

September 1997

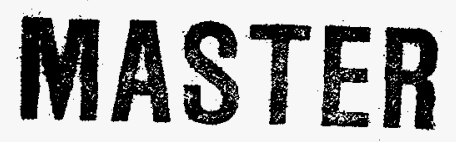

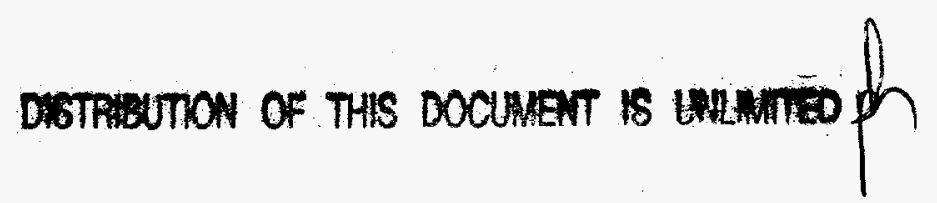

Prepared for the U.S. Department of Energy

Assistant Secretary for Energy Efficiency and Renewable Energy (EE)

Under DOE Idaho Operations Office

Contract DE-AC07-94ID13223 


\section{DISCLAIMER}

This report was prepared as an account of work sponsored by an agency of the United States Government. Neither the United States Government nor any agency thereof, nor any of their employees, makes any warranty, express or implied, or assumes any legal liability or responsibility for the accuracy, completeness, or usefulness of any information, apparatus, product, or process disclosed, or represents that its use would not infringe privately owned rights. Reference herein to any specific commercial product, process, or service by trade name, trademark, manufacturer, or otherwise does not necessarily constitute or imply its endorsement, recommendation, or favoring by the United States Government or any agency thereof. The views and opinions of authors expressed herein do not necessarily state or refiect those of the United States Government or any agency thereof. 


\section{DISCLAIMER}

Portions of this document may be illegible electronic image products. Images are produced from the best available original document. 


\section{CONTENTS}

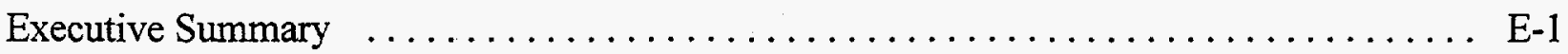

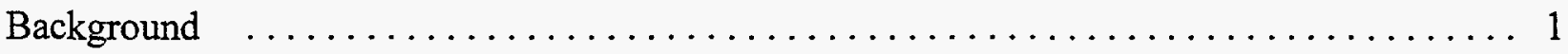

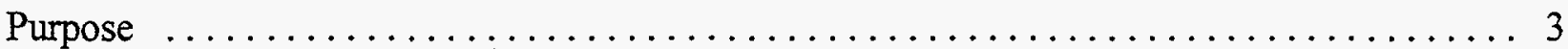

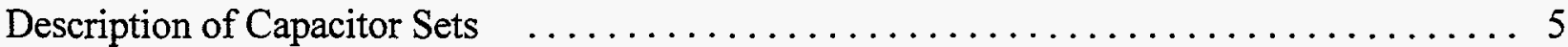

Set \#1 (1 capacitor received September 1,1996$) \quad \ldots \ldots \ldots \ldots \ldots \ldots \ldots \ldots \ldots$

Set \#2 (3 capacitors received October 1,1996$) \quad \ldots \ldots \ldots \ldots \ldots \ldots \ldots \ldots \ldots$

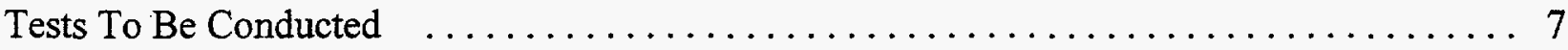

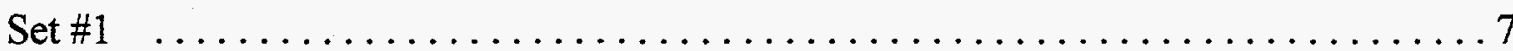

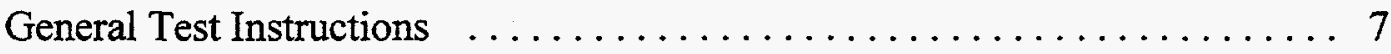

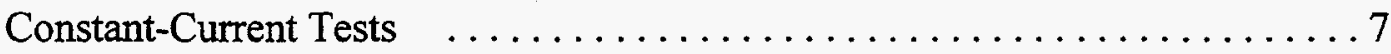

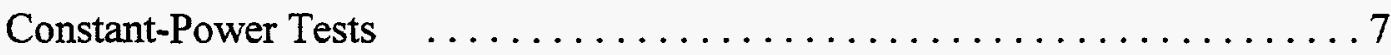

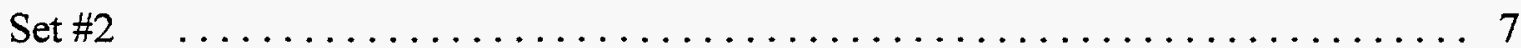

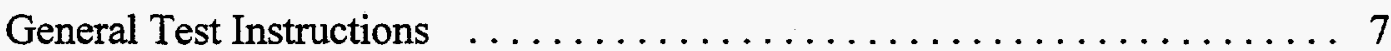

Constant-Current Tests $\ldots \ldots \ldots \ldots \ldots \ldots \ldots \ldots \ldots \ldots \ldots$

Constant-Power Tests $\ldots \ldots \ldots \ldots \ldots \ldots \ldots \ldots \ldots \ldots \ldots \ldots, 8$

Capacitor Testing Fundamentals $\ldots \ldots \ldots \ldots \ldots \ldots \ldots \ldots \ldots \ldots \ldots \ldots \ldots \ldots \ldots \ldots \ldots \ldots$

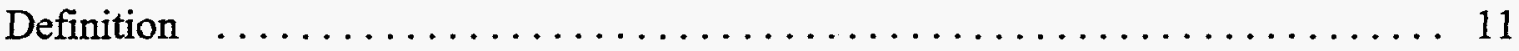

Energy and Power Supplied By A Capacitor $\ldots \ldots \ldots \ldots \ldots \ldots \ldots \ldots \ldots \ldots \ldots \ldots \ldots \ldots \ldots$

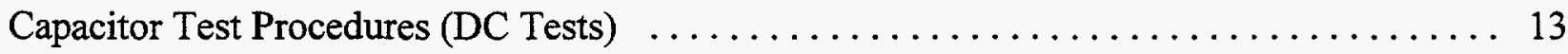

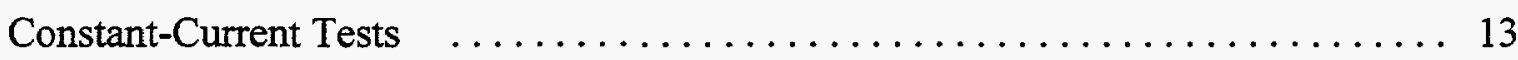

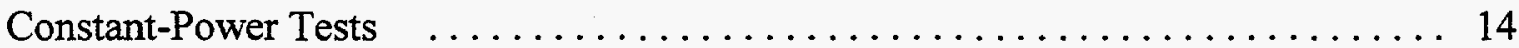

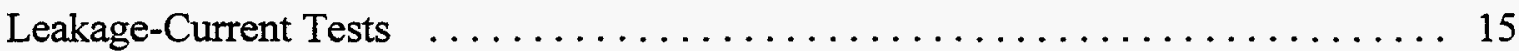

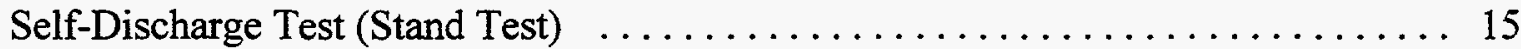

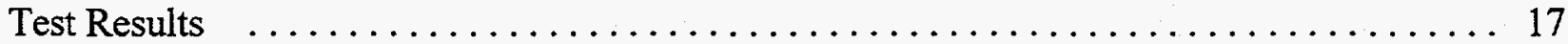

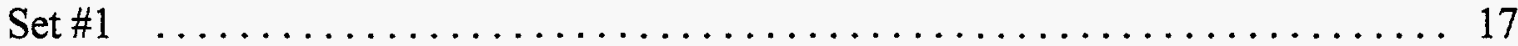

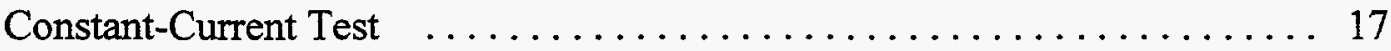

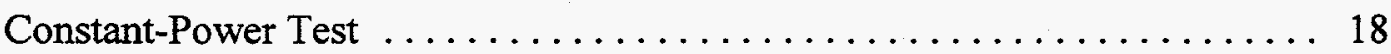

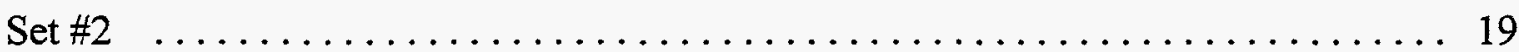

Constant-Current and Constant-Power Tests $\ldots \ldots \ldots \ldots \ldots \ldots \ldots \ldots$

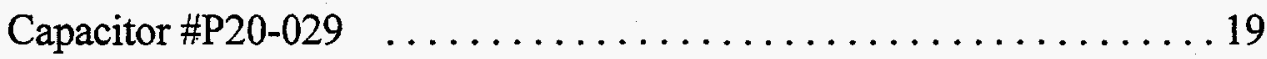

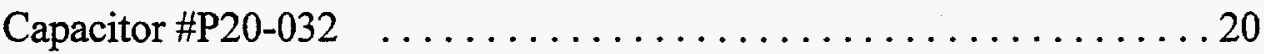

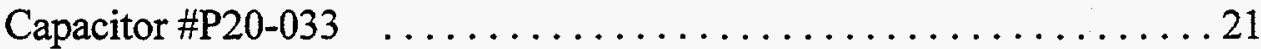

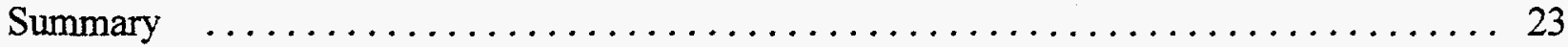

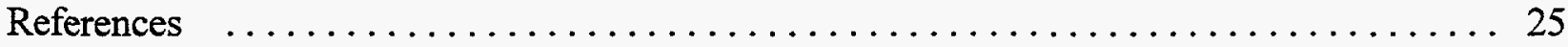




\section{FIGURES}

1. Photograph of Federal Fabrics-Fibers electrochemical capacitor (\#P18-196) . . . . . 3

2. Photograph of Federal Fabrics-Fibers electrochemical capacitors

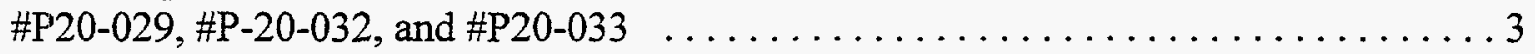

\section{APPENDICES}

A. Graphic Figures for Federal Fabrics-Fibers Capacitors \#P18-196,

$\#$ P20-029, \#P20-032, and \#P20-033 


\section{EXECUTIVE SUMMARY}

Two sets of capacitors (Set \#1 and Set \#2) were received for testing by the INEEL Automotive Systems and Technology Department from Federal Fabrics-Fibers. ${ }^{1-6}$ The capacitors were made up of several components including $\mathrm{Ni}$ and conductive plastic current collectors, a carbonaceous electrode material (bi-polar or mono-polar Z-axis carbon fibers), and a polypropylene separator and casing. These components were fabricated and then assembled to make the final packaged capacitor. The capacitors used an aqueous electrolyte containing $\mathrm{KOH}$.

Federal Fabrics-Fibers rated the one capacitor (\#P18-192) received for Set \#1 at $1 \mathrm{~V}$ with a capacitance of $13.5 \mathrm{~F}$; its as-tested weight was $41.5 \mathrm{~g}(0.0415 \mathrm{~kg})$; the carbon weight was $0.466 \mathrm{~g}$. Constant-current and constant-power tests were conducted on the capacitor; the test parameters were set according to the rating of the device. The constant-current tests were the first of the tests to be conducted and data was acquired using four, one-cycle test sequences consisting of a constant-current charge of $0.1 \mathrm{~A}$ with a voltage range of $0 \mathrm{~V}$ to $1 \mathrm{~V}$, followed by a 10 second hold at $1 \mathrm{~V}$, and then constant-current discharges at $0.1 \mathrm{~A}, 0.25 \mathrm{~A}, 0.5 \mathrm{~A}$ and $1.0 \mathrm{~A}$. Based on these data the capacitance was calculated to range from $10.49 \mathrm{~F}$ at $0.1 \mathrm{~A}$ to $7.43 \mathrm{~F}$ at $1.0 \mathrm{~A}$. From the constant-current tests the measured equivalent series resistance (ESR) for the capacitor varied from 149.4 milliohms at $0.1 \mathrm{~A}$ to 32.4 milliohms at $1.0 \mathrm{~A}$. The constant-current charging and discharging of this capacitor deviated from that expected based on an idealcapacitor model, in that the voltage as a function of time for the charge and discharge portions of the test were somewhat nonlinear. The constant-current tests permitted the calculation of the the ideal-stored specific energies and specific powers of the capacitor. The values ranged from $3.51 \times 10^{-2} \mathrm{~W} \cdot \mathrm{h} / \mathrm{kg}$ and $3.35 \times 10^{-4} \mathrm{~W} / \mathrm{kg}$ for the $0.10 \mathrm{~A}$ constant-current discharge test to $2.49 \times 10^{-2} \mathrm{~W} \cdot \mathrm{h} / \mathrm{kg}$ and $3.35 \times 10^{-3} \mathrm{~W} / \mathrm{kg}$ at $1.0 \mathrm{~A}$.

One constant-power test was conducted using a $0.1 \mathrm{~A}$ constant-current charge from $0 \mathrm{~V}$ to $1 \mathrm{~V}$, followed by a 0.0418 watt constant-power discharge from $1 \mathrm{~V}$ to $0 \mathrm{~V}$. The corresponding specific energies and specific powers ( $1 \mathrm{~V}$ to $0.5 \mathrm{~V}$ discharge range) were determined to be $1.75 \times 10^{-2} \mathrm{~W} \cdot \mathrm{h} / \mathrm{kg}$ and $1.01 \mathrm{~W} / \mathrm{kg}$ respectively. During this test the tester erroneously caused the cell polarity to be reversed and discharged the capacitor to $-3.3 \mathrm{~V}$ at approximately $12.5 \mathrm{~A}$. The constant-power test was repeated with correct tester programming and resulted in specific energies and powers ( $1 \mathrm{~V}$ to $0.5 \mathrm{~V}$ discharge range) measured to be $8.19 \times 10^{-3} \mathrm{~W} \cdot \mathrm{h} / \mathrm{kg}$ at $1.01 \mathrm{~W} / \mathrm{kg}$; the specific energy value had decreased by $53 \%$ after the anomalous constant-power test. The constant-current test at $0.1 \mathrm{~A}$ charge and discharge was then rerun to ascertain any changes in the capacitor's capacitance and ESR. The measured capacitance had decreased from $10.49 \mathrm{~F}$ to $6.24 \mathrm{~F}$, and the ESR had increased from 149.6 milliohms to 259.4 milliohms 
following the anomalous constant-power test. Further testing was terminated at this point due to the apparent damage to the capacitor during the constant-power test.

Federal Fabrics-Fibers rated the three (3) capacitors in Set \#2 at $1 \mathrm{~V}$ (\#P20-029, \#P20-032 and \#P20-033) with capacitances of:

- $\quad \# P 20-029$ at $26.0 \mathrm{~F}$

- $\quad \# \mathrm{P} 20-032$ at $14.0 \mathrm{~F}$

- $\quad \# P 20-033$ at $7.7 \mathrm{~F}$

Their as-tested weights were:

- $\quad 39.393 \mathrm{~g}(0.039393 \mathrm{~kg})$

- $\quad 36.626 \mathrm{~g}(0.036626 \mathrm{~kg})$

- $\quad 38.424 \mathrm{~g}(0.038424 \mathrm{~kg})$, respectively.

The dry carbon weight used in each of these capacitors was:

- $\quad 0.766 \mathrm{~g}$

- $\quad 0.353 \mathrm{~g}$

- $\quad 0.254 \mathrm{~g}$, respectively.

Constant-current and constant-power tests were conducted on the capacitors; the test parameters set according to the rating of the devices. The constant-current tests were the first of the tests to be conducted and data was acquired using three-cycle test sequences with each cycle consisting of a constant-current charge of $0.1 \mathrm{~A}$ with a voltage range of $0 \mathrm{~V}$ to $1 \mathrm{~V}$, followed by a 10 second hold at $1 \mathrm{~V}$, and then constant-current discharges ranging from 50 milliamperes to 800 milliamperes, followed by a 10 seconds hold at $0 \mathrm{~V}$. Based on these data, the capacitance and equivalent series resistance for each capacitor was calculated and plotted as a function of the constant-current discharge current. For capacitor \#P20-029 the capacitance varied from $9.29 \mathrm{~F}$ to $4.35 \mathrm{~F}$ and its ESR ranged from $1.065 \mathrm{ohms}$ to $0.454 \mathrm{ohms}$. The capacitance of capacitor \#P20-032 varied from $13.2 \mathrm{~F}$ to $8.0 \mathrm{~F}$ and its ESR ranged from $0.501 \mathrm{ohms}$ to $0.241 \mathrm{ohms}$. Capacitor \#P20-033 had capacitance values varying from $7.93 \mathrm{~F}$ to $6.30 \mathrm{~F}$ and ESR values spanning $0.346 \mathrm{ohms}$ to $0.134 \mathrm{ohms}$. The constant-current charging and discharging of these capacitors deviated from that expected based on an ideal-capacitor model in that the voltage as a function of time for the charge and discharge portions of the test was somewhat nonlinear. During charging of the capacitors at 0.1 A constant-current, it was generally observed that their 
voltage increased more rapidly at short charge times than the ideal-capacitor model would predict based on their measured capacitance and ESR values. At longer charging times the voltage increased more slowly than predicted by the ideal-capacitor model. During constant-current discharging the capacitors' voltage decreased faster at short discharge times and slower at longer discharge times than the behavior predicted by the ideal-capacitor model. Constant-power tests were run on all three capacitors at constant-power discharge levels ranging from 0.05 watt to 0.30 watt over the voltage range of $1 \mathrm{~V}$ to $0.5 \mathrm{~V}$. Capacitor \#P20-029 had specific energies and powers ranging from $1.19 \times 10^{-2} \mathrm{~W} \cdot \mathrm{h} / \mathrm{kg}$ at $1.27 \mathrm{~W} / \mathrm{kg}$ to $8.89 \times 10^{-3} \mathrm{~W} \cdot \mathrm{h} / \mathrm{kg}$ at $3.17 \mathrm{~W} / \mathrm{kg}$. The specific energies and powers for capacitor \#P20-032 varied from $2.56 \times 10^{-2} \mathrm{~W} \cdot \mathrm{h} / \mathrm{kg}$ at $1.37 \mathrm{~W} / \mathrm{kg}$ to $1.31 \times 10^{-2} \mathrm{~W} \cdot \mathrm{h} / \mathrm{kg}$ at $8.19 \mathrm{~W} / \mathrm{kg}$. These same parameters for capacitor \#P20-033 were $1.36 \times 10^{-2} \mathrm{~W} \cdot \mathrm{h} / \mathrm{kg}$ at $1.30 \mathrm{~W} / \mathrm{kg}$ and $1.04 \times 10^{-2} \mathrm{~W} \cdot \mathrm{h} / \mathrm{kg}$ at $5.21 \mathrm{~W} / \mathrm{kg}$. 
E-4 


\section{BACKGROUND}

The electrochemical capacitor devices described in this report were deliverables from the U.S. Department of Energy - Idaho Operations Office (DOE-ID) Contract No. DE-AC0794ID13405 as part of the U.S. Department of Energy's (DOE) High Power Energy Storage Program. The Idaho National Engineering and Environmental Laboratory(INEEL) has the responsibility for technical management, testing, and evaluation of high-power batteries and electrochemical capacitors under this Program. The DOE is currently developing various electrochemical capacitors as candidate power assist devices for the Partnership for a New Generation of Vehicles (PNGV) fast response engine requirement. ${ }^{7}$ This contract with Federal Fabrics-Fibers was intended to evaluate the use of their novel Z-axis carbon fiber materials as candidate electrodes for electrochemical capacitors. Deliverables were sent to the INEEL's Energy Storage Technologies (EST) Laboratory for independent testing and evaluation. This report describes performance testing on four selected devices delivered over a 2-year period. Due to the highly experimental nature of the packages, life cycle testing was not conducted. 


\section{PURPOSE}

The purpose of this report is to present the electrical performance for four electrochemical capacitors supplied by Federal Fabrics-Fibers received for testing at the INEEL during September and October, 1996 (see Figures 1 and 2). All tests were conducted in the EST Laboratory which is operated and supervised by engineers and technicians as part of the Automotive Systems \& Technology Department's program.

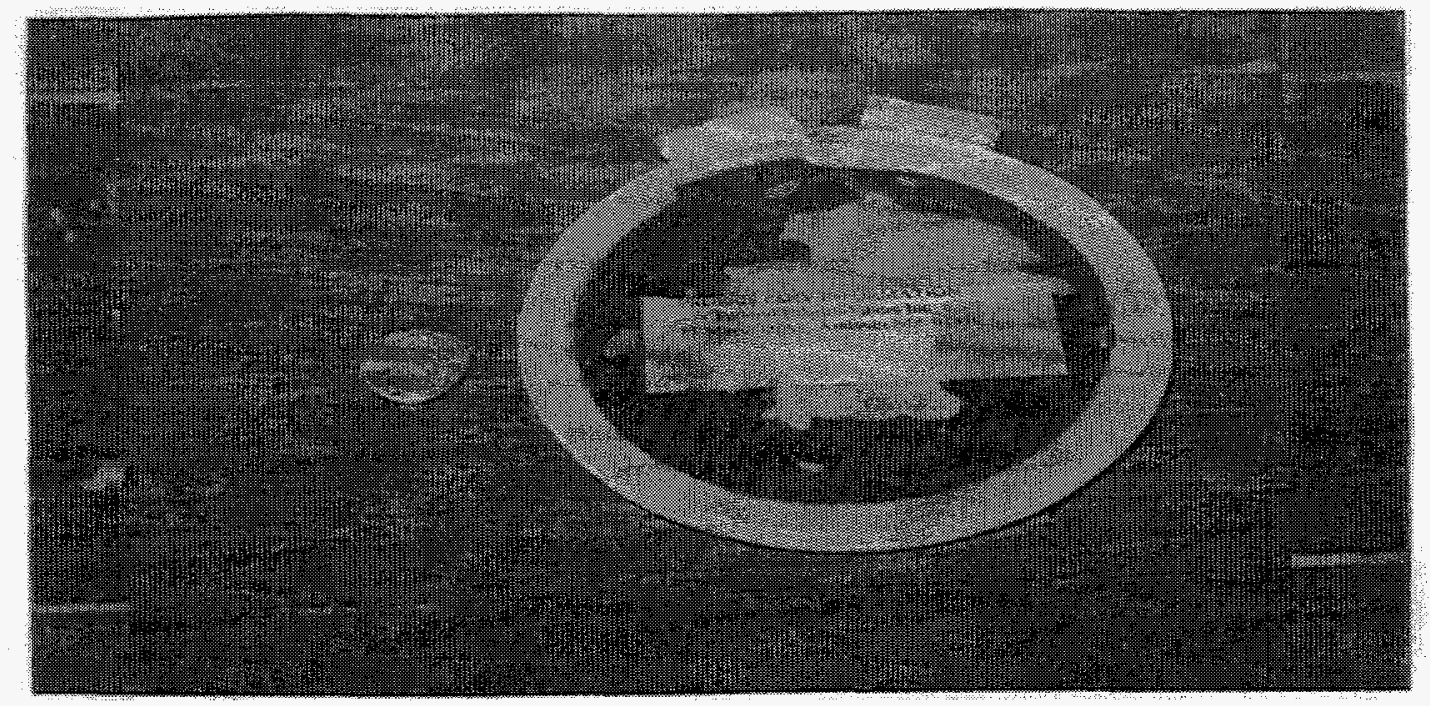

Figure 1. Photograph representative of the Federal Fabrics-Fibers electrochemical capacitor \#P18-196. [96-714-1-12]

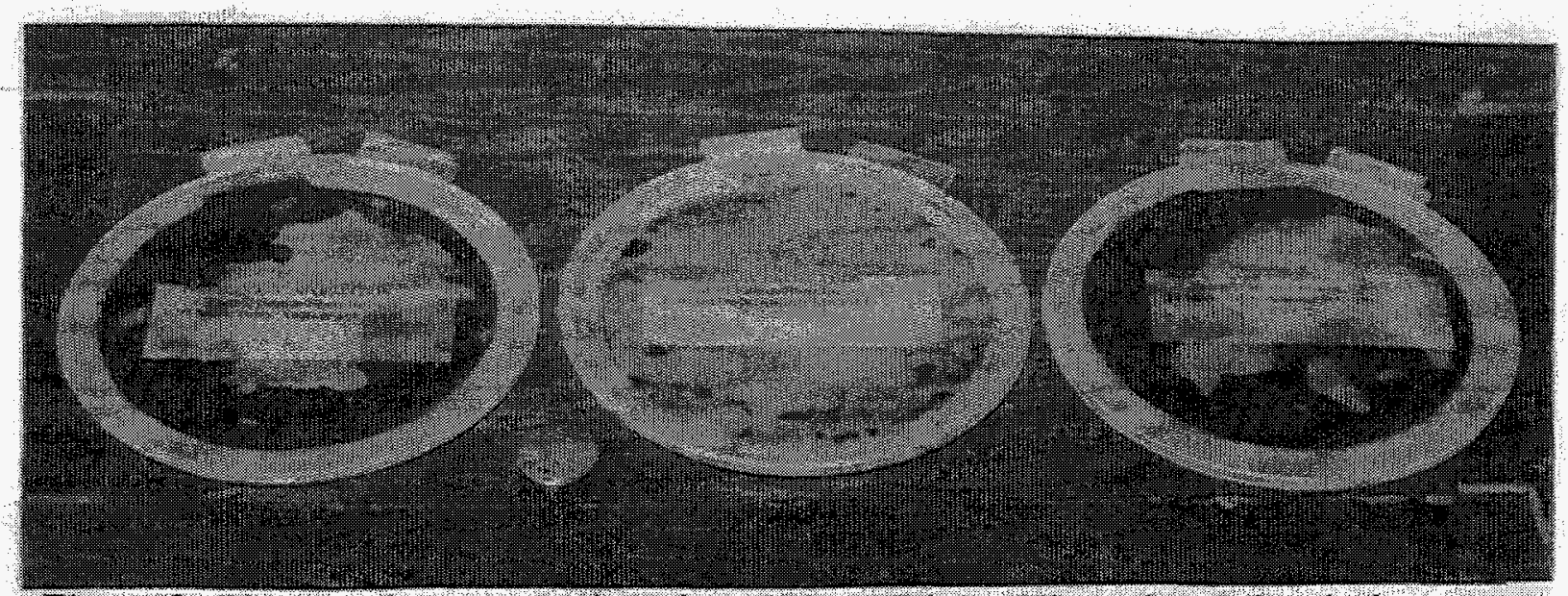

Figure 2. Photograph representative of the Federal Fabrics-Fibers electrochemical capacitors \#P20-029, \#P20-032, and \#P20-033. [96-714-1-10] 


\section{DESCRIPTION OF CAPACITOR SETS}

The capacitors had the following specifications as supplied by Federal Fabrics-Fibers:

\section{Set \#1 (1 capacitor) received September 1,1996}

Voltage Rating: $\quad 1 \mathrm{~V}$

Capacitance: $\quad 13.5 \mathrm{~F}$

General Fabrication Information:

The capacitor was made up of several components including $\mathrm{Ni}$ and proprietary current collectors, a carbonaceous electrode material (bi-polar or mono-polar Z-axis carbon fibers), and a polypropylene separator and casing. The separator is cut to the desired size and shape from a $0.12 \mathrm{~mm}$ thick polypropylene filter with 10 micron pores supplied by Gelman Sciences, Inc. These components are fabricated and then assembled to make the final packaged capacitor. The capacitor used an aqueous electrolyte containing $\mathrm{KOH}$. No extra precautions were taken to insure that the carbon used in this capacitor was fully dried. The carbon weight was given as $0.466 \mathrm{~g}$. The electrode diameters are $9.5 \mathrm{~cm}$ (3.74 inches) and the projected cross sectional areas are $70 \mathrm{~cm}^{2}\left(10.85 \mathrm{in}^{2}\right)$. This capacitor had undergone extensive testing at Federal Fabrics-Fibers prior to shipment to the INEEL

\section{Set \#2 (3 capacitors) received October 1,1996}

Voltage Rating: $1 \mathrm{~V}$

General Specifications:

Capacitor \#P20-029: capacitance $=25.95 \mathrm{~F}$; dry carbon weight $=0.766 \mathrm{~g}$; assembled capacitor weight $=39.698 \mathrm{~g}$

Capacitor \#P20-032: capacitance $=14.01 \mathrm{~F}$; dry carbon weight $=0.353 \mathrm{~g}$; assembled capacitor weight $=36.427 \mathrm{~g}$

Capacitor \#P20-033: capacitance $=7.7 \mathrm{~F}$; dry carbon weight $=0.254 \mathrm{~g}$; assembled capacitor weight $=38.434 \mathrm{~g}$

General Fabrication Information:

The components were fabricated and then assembled to make the final packaged capacitor. The capacitors used an aqueous electrolyte containing $\mathrm{KOH}$. The separator is cut to 
the desired size and shape from a $0.12 \mathrm{~mm}$ thick polypropylene filter with 10 micron pores supplied by Gelman Sciences, Inc. The electrodes used in the capacitors were dried overnight in vacuum at $60^{\circ} \mathrm{C}$. The electrode diameters are $9.5 \mathrm{~cm}$ (3.74 inches) and the projected cross sectional areas are $70 \mathrm{~cm}^{2}\left(10.85 \mathrm{in}^{2}\right)$. Capacitor \#P20-032 utilized a more aggressively expanded and lighter-weight $\mathrm{Ni}$ electrode. Each capacitor had undergone extensive testing at Federal Fabrics-Fibers prior to shipment to the INEEL. 


\section{TESTS TO BE CONDUCTED}

Set\#1

1. General Test Instructions:

- After removing the devices from their packaging weigh the capacitor to the nearest $0.1 \mathrm{~g}$ (if possible to the nearest $0.01 \mathrm{~g}$ ) and record results.

- Charge at a constant-current of 0.1 A (100 milliamperes).

- Clamp voltage for 10 seconds at the charge and discharge voltage end points specified on each test cycle.

2. Constant-Current Tests:

- Voltage limits are 1.0 to $0.0 \mathrm{~V}$.

- Begin discharging capacitor at constant currents of $0.10,0.25,0.50$ and 1.0 ampere until a discharge time of approximately 10 seconds is attained.

3. Constant-Power Tests:

- Voltage limits are 1.0 to $0.0 \mathrm{~V}$.

- Discharge capacitor at constant-powers such that the discharge time would not be less than approximately 10 seconds.

\section{$\underline{\text { Set \#2- }}$}

1. General Test Instructions:

- After removing the devices from their packaging weigh each capacitor to the nearest $0.1 \mathrm{~g}$ (if possible to the nearest $0.01 \mathrm{~g}$ ) and record results.

- The capacitor number is scribed on the side of the polypropylene container. The "+" and "-" terminals are also marked on each capacitor. Test each capacitor by holding upright in a clamping device suitable for grasping the device but not perforating the polypropylene. No specific instructions were provided as to the amount of clamping force, if any, to apply to the capacitors during testing.

- Charge capacitor at $0.100 \mathrm{~A}(100 \mathrm{~mA})$ constant current. 
- Clamp voltage for 10 seconds at the charge and discharge voltage endpoints specified on each test cycle.

- For the constant-current and constant-power tests complete three cycles at each test condition.

2. Constant-Current Tests

- Voltage limits are 1.0 to $0.0 \mathrm{~V}$.

- Begin discharging the capacitor at constant-currents of $0.050,0.100,0.200,0.400$, $0.800,1.000$ and $2.000 \mathrm{~A}(50,100,200,400,800,1000$ and $2000 \mathrm{~mA}$ respectively). Based on the supplier provided capacitances and a voltage range of 1.0 to $0.0 \mathrm{~V}$ these constant-current discharge values would correspond to discharge times of:

\#P20-029: $\quad 520,360,65,32.5,26$ and 13 seconds respectively. The constantcurrent can be increased or decreased from those specified above until a discharge time of approximately 10 seconds is achieved; at this point the test should be terminated.

\#P20-032: $\quad 280,140,70,35,17.5,14$ and 7 seconds respectively. The constant-current can be increased or decreased from those specified above until a discharge time of approximately 10 seconds is achieved; at this point the test should be terminated.

\#P20-033: $\quad 154,77,38.5,19.25,9.63,7.7$ and 3.85 seconds respectively. The constant-current can be increased or decreased from those specified above until a discharge time of approximately ten seconds is achieved; at this point the test should be terminated.

3. Constant-Power Tests

- Voltage limits are $1.0 \mathrm{~V}$ to $0.5 \mathrm{~V}$.

- Due to the different rated capacitance of each of the three devices the following tests should be conducted on the respective capacitors:

\#P20-029: Test at constant-powers of $0.10,0.20,0.40,0.80$ and 1.00 watt. The higher end of the constant-power test range can be increased or decreased in order to achieve a constant power discharge time of approximately 10 seconds.

\#P20-032: Test at constant-powers of $0.05,0.10,0.20,0.40$ and 0.60 watt. The higher end of the constant-power test range can be increased or decreased in order to achieve a constant-power discharge time of approximately 10 seconds. 
\#P20-033: Test at constant-powers of $0.05,0.075,0.10,0.15$ and 0.30 watt. The higher end of the constant-power test range can be increased or decreased to achieve a constant-power discharge time of approximately 10 seconds. 


\section{CAPACITOR TESTING FUNDAMENTALS ${ }^{8}$}

\section{Definition}

"Capacitance is a measure of the ability of a device, a capacitor, to store energy in the form of separated charge or as an electric field."

The capacitance $\mathrm{C}$ of a capacitor is defined as the ratio of the charge $\mathrm{Q}$ (in units of coulombs, $1 \mathrm{e}^{-}=1.602 \times 10^{-19}$ coulomb) on either of two spatially separated conductors to the potential difference $\mathrm{V}_{\mathrm{ab}}$ (in volts) between the conductors.

$$
\mathrm{C}=\mathrm{Q} / \mathrm{V}_{\mathrm{ab}}
$$

The unit of capacitance is the farad, defined as one coulomb per volt. A farad is also defined to be one ampere-second/volt. A first-order model for an electrochemical capacitor includes a capacitor $C$ in series with a resistor $R_{s}$ and a series inductor $L$. A resistor $R_{p}$ in parallel with the capacitor is also included in this model.

$R_{s}$ is usually referred to as the equivalent series resistance (ESR) and contributes to energy loss during capacitor charging and discharging. $R_{p}$ simulates energy loss due to capacitor self-discharge and is often referred to as the leakage-current resistance. $L$ is the inductance of the capacitor that results primarily from its construction and is usually small. Capacitance (in farads) as defined above can be expressed as:

$$
\mathbf{C}=\mathbf{Q} / \mathrm{V}
$$

where $\mathrm{Q}$ is the charge on the capacitor in coulombs and $\mathrm{V}$ is the potential difference in volts. For a series $R C$ circuit (neglecting $R_{p}$ and $L$ ) the voltage as a function of time can be expressed as:

$$
\mathbf{V}_{0}-\mathbf{V}(\mathbf{t})=I^{*} \mathbf{R}_{\mathrm{s}}+\left[\mathbf{Q}_{0}-\mathbf{Q}(\mathbf{t})\right] / C
$$

where $V_{0}$ is the initial voltage across the capacitor, $Q_{0}$ is the initial charge on the capacitor having a capacitance $C ; I$ is the current flowing in the circuit and $R_{s}$ is the series resistance. During a constant-current charging test, $I=I_{c}=$ constant set by the test during charging; $V_{o}=0$ if the capacitor is totally discharged or $\mathrm{V}_{0}=\mathrm{V}_{0}$ if the capacitor has already been charged to a voltage $\mathrm{V}_{\mathrm{o}}$. For $\mathrm{Q}_{\mathrm{o}}=0$ and $\mathrm{Q}(\mathrm{t})=\mathrm{I}_{\mathrm{c}} \mathrm{t}$ or if $\mathrm{Qo}=\mathrm{Qo}$ then $\mathrm{Q}(\mathrm{t})=\mathrm{Q}_{\mathrm{o}}+\mathrm{I}_{\mathrm{c}} \mathrm{t}$ so that:

$$
\mathbf{V}_{\mathrm{c}}(\mathbf{t})=\left(\mathbf{V}_{\mathrm{o}}+\mathbf{I}_{\mathrm{c}} \mathbf{R}_{\mathrm{s}}+\left(\mathbf{I}_{\mathrm{c}} / \mathbf{C}\right) \mathbf{t}\right.
$$


During a constant-current discharge test $V(t=0)=V_{0}, I_{d}=$ constant set by the test (note that by convention a discharge current is negative in sign as compared to a charging current); $Q_{0}=V_{0} C$ and $Q(t)=\left(Q_{0}-I_{d} t\right) / C$ so that:

$$
V_{d}(t)=\left(V_{o}-I_{d} R_{s}\right)-\left(I_{d} / C\right) t
$$

The terms $\left(V_{o}+I_{c} R_{s}\right)$ for charging and $\left(V_{o}-I_{d} R_{s}\right)$ for discharging can be used to calculate the Equivalent Series Resistance (ESR) during charging and discharging of the capacitor by the $\mathrm{IR}_{\text {step }}$ method that monitors the voltage on the capacitor immediately after the current applied to the capacitor has been changed.

\section{Energy and Power Supplied by a Capacitor}

For a capacitor having a capacitance $C$ and charged to an initial voltage $V_{i}$ that is then discharged to a final voltage $V_{f}$, the energy (in joules) extracted is:

$$
E=(1 / 2) C V_{i}^{2}\left[1-\left(V_{f} / V_{i}\right)^{2}\right]
$$

For example, if the capacitor is discharged to $1 / 2$ of its initial voltage $V_{f}=1 / 2 V_{i}$ then the energy withdrawn is $3 / 4$ of the maximum available, i.e.:

$$
E=(3 / 4)(1 / 2) C V_{i}^{2}
$$

Similarly, the total energy available in the capacitor when $V_{f}=0$ is then:

$$
E=(1 / 2) C V_{i}^{2}
$$

Since power, $\mathrm{P}$ [in watts, where 1 watt $=1$ ampere $\times 1$ volt $=(1$ coulomb $/$ second $) \times(1$ joule/coulomb) $=1$ joule/second], is equal to the energy expended over a time interval $\Delta t$ (in seconds) then:

$$
\mathbf{P}=\mathbf{E} / \Delta \mathbf{t}
$$

The specific energy and specific power (mass and volume densities) can be obtained by dividing by the mass (in $\mathrm{kg}$ ) or volume (in liters) of the capacitor respectively. 


\section{CAPACITOR TEST PROCEDURES (DC TESTS)}

\section{Constant-Current Test}

The constant-current test allows the determination of the following capacitor properties:
a. Capacitance.
b. Equivalent series resistance (ESR).
c. Working (also known as the ideal) energy and power densities.

The basic test cycle is:

- Charge the capacitor at a constant specified current to the specified working voltage;

- Hold at this voltage for 10 to 20 seconds;

- Discharge the capacitor at a constant-current to a specified voltage (generally to $0 \mathrm{~V}$ ).

- Hold at this voltage for 10 to 20 seconds.

These steps constitute one test cycle that is generally repeated three times. The currents ( $\mathrm{I}_{\text {test }}$ in amperes) to use for these tests are generally kept such that the charge and discharge times are greater than or approximately equal to 10 seconds.

The capacitance of the capacitor can be calculated using:

$$
\mathbf{C}=\left(\mathbf{I}_{\text {test }}\right)\left(\mathbf{t}_{\text {test }}\right) / \Delta \mathbf{V}
$$

where $\mathrm{I}_{\text {test }}$ is the constant-current used during the test (in amperes), $\Delta \mathrm{V}$ (in volts) is the voltage range used in the test and $t_{\text {test }}$ is the measured time in seconds that it takes the capacitor to discharge from the starting voltage (usually the maximum specified working voltage) to the ending voltage.

The working (also referred to as the ideal-stored) mass and volume energy densities can then be calculated using:

$$
E_{w} / \text { Mass }=(1 / 2)\left(I_{\text {test }}\right)\left(t_{\text {test }}\right) \Delta V /(3600 * M)
$$

in $\mathrm{W} \cdot \mathrm{h} / \mathrm{kg}$, where $\mathrm{M}$ is the mass of the capacitor in $\mathrm{kg}$ and the factor 3600 converts time in seconds to time in hours. The volumetric energy density is given by: 


$$
\mathbf{E}_{\mathrm{w}} / \text { Volume }=(1 / 2)\left(\mathrm{I}_{\text {test }}\right)\left(\mathrm{t}_{\text {test }}\right) \Delta \mathrm{V} /\left(3600 * \mathrm{~V}_{\text {cap }}\right)
$$

in $W \cdot h / l$, where $V_{\text {cap }}$ is the volume in liters of the capacitor.

In the constant-current tests the current (I) is suddenly changed at the beginning and end of the charge/discharge portions of the test cycle. The equivalent series resistance (ESR) is calculated at the beginning of the charge and the discharge cycle using:

$$
\mathrm{ESR}=(\Delta \mathrm{V})_{\mathrm{IR} \mathrm{step}} / \mathbf{I}_{\mathrm{IR} \mathrm{step}}
$$

where $(\Delta V)_{\mathbb{I R ~ s t e p ~}}$ is the voltage change that occurs during the change in the current $I_{\mathbb{R} \text { step. }}$. The ESR value is given in ohms and is generally found to vary with the constant-current charge or discharge test value.

\section{Constant-Power Test}

The constant-power test allows the determination of the specific energies $(\mathrm{W} \cdot \mathrm{h} / \mathrm{kg}$ and $\mathrm{W} \cdot \mathrm{h} / \mathrm{L}$ ) and specific powers (W/kg and $\mathrm{W} / \mathrm{L}$ ) under different constant-power discharge conditions. The basic test cycle is:

- The capacitor is charged at a constant-current to a specified voltage;

- The capacitor is held at this voltage for 10 to 20 seconds;

- A constant-power discharge is started and the capacitor is discharged to a specified voltage (generally to $1 / 2$ the working voltage that results in the extraction of $3 / 4$ of the total energy available from the capacitor);

- The capacitor is then held at this voltage for 10 to 20 seconds.

These steps constitute one test-cycle that is generally repeated three times during an actual test.

For each constant-power discharge portion of the test cycle, the energy (W·s) is calculated by summing $V^{*} I^{*} \Delta t$ ( $V$ in volts, $I$ in amperes and $\Delta t$ in seconds) during the discharge. The specific energies (mass and volume) are then calculated using:

$$
E_{s} / \text { Mass }=\Sigma[V(t) * I(t) * \Delta t]_{\text {discharge }} /(3600 * M)
$$

in $\mathrm{W} \cdot \mathrm{h} / \mathrm{kg}$ where $\mathrm{M}$ is the mass of the capacitor in $\mathrm{kg}$, and

$$
\mathbf{E}_{\mathrm{s}} / \text { Volume }=\Sigma\left[\mathbf{V}(\mathbf{t})^{*} \mathbf{I}(\mathbf{t})^{*} \Delta t\right]_{\text {discharge }} /\left(3600^{*} \mathbf{V}_{\text {cap }}\right)
$$


in $\mathrm{W} \cdot \mathrm{h} / \mathrm{L}$ where $\mathrm{V}_{\text {cap }}$ is the volume of the capacitor in liters.

Under conditions of a constant-power test the specific power, $\mathrm{P}_{\mathrm{s}}$, is set by the test and the specific power densities corresponding to the specific energy densities of equations (13) and (14) would be this power divided by the mass of the capacitor (in $\mathrm{kg}$ ) or the volume of the capacitor (in liters) respectively.

\section{Leakage-Current Test}

The leakage-current test measures the time dependent value of the parallel resistor, $R_{p}$, in the simple circuit model of the capacitor.

$$
\mathbf{R}_{\mathrm{p}}(\mathbf{t})=\mathbf{V}_{\mathrm{i}} \mathbf{I}(\mathbf{t})
$$

where $V_{i}$ is the initial voltage on the capacitor and $I(t)$ is the time dependent current required to maintain this voltage at its initial value $\mathrm{V}_{\mathrm{i}}$.

\section{Self-Discharge Test (also known as the Stand Test)}

The self-discharge test allows the determination of the self-dissipation of the capacitor, i.e. those internal processes that cause the capacitor to discharge when not connected to a load. The test measures the time dependent self-discharge energy loss factor $\operatorname{SDLF}(t)$ that results from measuring the time dependence of the voltage of the capacitor, $V(t)$, when the capacitor is not connected to a load:

$$
\operatorname{SDLF}(t)=1-\left[V(t)^{2} / V_{i}^{2}\right]
$$

where $\mathrm{V}_{\mathrm{i}}$ is the initial voltage on the capacitor. The $\operatorname{SDLF}(\mathrm{t})$ value permits the calculation of the amount of energy remaining in the capacitor [by using equations (5) or (7)] after it has been charged to a voltage $V_{i}$ and then placed in a condition where it is not connected to an external load. 


\section{TEST RESULTS}

\section{Set \#1}

Capacitor \#P18-192 had a measured as-tested weight of $42.5 \mathrm{~g}(0.0425 \mathrm{~kg})$

\section{Constant-Current Test}

The first test that was run on this capacitor was the Constant-Current Test. Four tests consisting of one cycle each were used in this study as are shown in Figure A-1. In this figure are shown the capacitor voltage (volts) as a function of test time (seconds) for constant-current discharge tests conducted at $0.1 \mathrm{~A}, 0.25 \mathrm{~A}, 0.5 \mathrm{~A}$ and $1.0 \mathrm{~A}$ over a voltage range of $1 \mathrm{~V}$ to $0 \mathrm{~V}$. A constant-current charge at $0.1 \mathrm{~A}$ was used to initially charge the capacitor for each test. The capacitor potential as a function of test time is shown in Figure A-2 for two of the complete charge/discharage cycles, with discharge currents of $0.1 \mathrm{~A}$ and $1.0 \mathrm{~A}$. As can be seen in Figure A-2, the $0.1 \mathrm{~A}$ constant-current charge steps are not exactly equal in shape and neither of them is a linear function of time as would be expected based on equation (3). The slope of the constant-current discharge curves are different as would be expected on the basis of the idealcapacitor model. However, the discharge curves are not quite linear functions of discharge time as would be expected based on this model [equation (4)]. These points are better illustrated in Figure A-3, where the measured capacitor potential as a function of test time for the constantcurrent charge $(0.1 \mathrm{~A})$ and the constant-current discharge $(0.1 \mathrm{~A})$ portion of the test cycle are compared with the ideal-capacitor model expressed by equations (3) and (4) respectively. The capacitance, $C$, and the values of the equivalent series resistance, $R_{c \text { and d }}$, used in these equations were $C=10.49 \mathrm{~F}$, and $\mathrm{R}_{\mathrm{c} \text { and } d}=0.150 \mathrm{ohms}$ determined as discussed below. From these comparisons it is clear that the capacitor takes longer to charge than an ideal-capacitor and it does so in a nonlinear manner. It also discharges more rapidly than an ideal-capacitor and in a nonlinear manner as a function of discharge time. Similarly, Figure A-4 shows the experimental and theoretical ideal-capacitor model of the capacitor potential as a function of discharge time during the $1.0 \mathrm{~A}$ constant-current discharge from $1 \mathrm{~V}$ to $0 \mathrm{~V}$. The values of $\mathrm{C}=7.43 \mathrm{~F}$ and $R_{d}=$ 0.0324 ohms were used in equation (4). Again it can be seen that the capacitor's voltage decreases faster (i.e., larger slope) than that of an ideal-capacitor at times shorter than approximately 2 seconds; at greater discharge times the voltage does not decrease as fast (i.e., smaller slope). 
Returning to Figure 1, the time it took the capacitor to discharge from $1 \mathrm{~V}$ to $0 \mathrm{~V}$ was 104.87 seconds at $0.1 \mathrm{~A}, 37.95$ seconds at $0.25 \mathrm{~A}, 16.86$ seconds at $0.5 \mathrm{~A}$, and 7.43 seconds at $1.0 \mathrm{~A}$. Using equation (9) the capacitance was calculated to be $10.49 \mathrm{~F}, 9.49 \mathrm{~F}, 8.43 \mathrm{~F}$ and $7.43 \mathrm{~F}$ respectively at these constant-current discharge values. These values of the capacitance as a function of constant-current discharge current are plotted in Figure A-5. The values of the equivalent series resistance (ESR) as calculated from the test data using equation (12) are 149.6 milliohms at $0.1 \mathrm{~A}, 64.7$ milliohms at $0.25 \mathrm{~A}, 60.4$ milliohms at $0.5 \mathrm{~A}$, and 32.4 milliohms at 1.0 A. These values are plotted in Figure A-6.

Values of the specific energies and specific powers of the capacitor were calculated, using equation (10), to be $3.51 \times 10^{-2} \mathrm{~W} \cdot \mathrm{h} / \mathrm{kg}$ and $3.35 \times 10^{-4} \mathrm{~W} / \mathrm{kg}$ for the $0.10 \mathrm{~A}$ constant-current discharge test, $3.18 \times 10^{-2} \mathrm{~W} \cdot \mathrm{h} / \mathrm{kg}$ and $8.37 \times 10^{-4} \mathrm{~W} / \mathrm{kg}$ at $0.25 \mathrm{~A}, 2.82 \times 10^{-2} \mathrm{~W} \cdot \mathrm{h} / \mathrm{kg}$ and $1.67 \times 10^{-3}$ $\mathrm{W} / \mathrm{kg}$ at $0.5 \mathrm{~A}$, and $2.49 \times 10^{-2} \mathrm{~W} \cdot \mathrm{h} / \mathrm{kg}$ and $3.35 \times 10^{-3} \mathrm{~W} / \mathrm{kg}$ at $1.0 \mathrm{~A}$. These values are plotted in Figure A-7.

\section{Constant-Power Test}

The constant-power test was then run on this capacitor using a $0.1 \mathrm{~A}$ constant-current charge and a $0.0418 \mathrm{~W}$ (41.8 milliwatts) constant-power discharge. The potential from $1 \mathrm{~V}$ to $0 \mathrm{~V}$ as a function of discharge time is shown in Figure A-8. Unfortunately, the tester was not correctly programed to limit the current during the constant-power discharge and thus it reversed the polarity on the capacitor to a value of $-3.3 \mathrm{~V}$ at 12.5 amperes. We were, however, able to use equation (13) to calculate the specific energy and specific power from the test data ( $1 \mathrm{~V}$ to 0.5 discharge range). The specific energy was $1.75 \times 10^{-2} \mathrm{~W} \cdot \mathrm{h} / \mathrm{kg}$ at a specific power of 1.01 $\mathrm{W} / \mathrm{kg}$. The constant-power discharge test at $0.0418 \mathrm{~W}$ was then rerun with correct programming of the tester; the potential as a function of discharge time is also shown in Figure A-8. The capacitor had obviously suffered an alteration in its properties during the previous, anomalous constant-power test. The calculated specific energy had decreased to $8.19 \times 10^{-3} \mathrm{~W} \cdot \mathrm{h} / \mathrm{kg}$ from $1.75 \times 10^{-2} \mathrm{~W} \cdot \mathrm{h} / \mathrm{kg}$; both values at the same specific power $1.01 \mathrm{~W} / \mathrm{kg}$. This corresponds to a decrease of $53 \%$ in the specific energy of the capacitor as a result of the anomalous constantpower test. A constant-current test at a constant-current of $0.1 \mathrm{~A}$ was then run. These data are shown in Figure A-9 which compares the capacitor voltage as a function of discharge time for the original $0.1 \mathrm{~A}$ constant-current test (same data as shown in Figure A-1) with its voltage behavior after the anomalous constant-power test. From these data and using equations (9) and 
(12) the value of the capacitance had decreased from $10.5 \mathrm{~F}$ to $6.24 \mathrm{~F}$ and the ESR value had increased to 259.4 milliohms from 149.6 milliohms. The specific energy had decreased to $2.09 \times 10^{-2} \mathrm{~W} \cdot \mathrm{h} / \mathrm{kg}$ from $3.51 \times 10^{-2} \mathrm{~W} \cdot \mathrm{h} / \mathrm{kg}$ (a $59.5 \%$ decrease); the specific power being the same in both cases and equal to $3.35 \times 10^{-4} \mathrm{~W} / \mathrm{kg}$.

No further tests were conducted on this device due to the deleterious influence of the anomalous constant-power test described above.

\section{Set \#2}

Measured as-tested weights for the three capacitors:

$$
\begin{array}{ll}
\text { \#P20-029: } & 39.393 \mathrm{~g}(0.039393 \mathrm{~kg}) \\
\text { \#P20-032: } & 36.626 \mathrm{~g}(0.036626 \mathrm{~kg}) \\
\text { \#P20-033: } & 38.424 \mathrm{~g}(0.038424 \mathrm{~kg})
\end{array}
$$

\section{Constant-Current and Constant-Power Tests}

Capacitor \#P20-029: Four constant-current tests consisting of three-cycles each were used in this study. A three-cycle constant-current test sequence using a $0.1 \mathrm{~A}$ constant-current charge and discharge is shown in Figure A-10. The capacitor was initially charged from $0.5 \mathrm{~V}$ to $1.0 \mathrm{~V}$; the voltage was held constant at this value for 10 seconds and then discharged to $0 \mathrm{~V}$. Recharging from $0 \mathrm{~V}$ to $1 \mathrm{~V}$ was then used in the remaining two cycles. The voltage behavior as a function of test time during the charge and discharge portions of the test cycle is not symmetrical, and it is not a linear function of time as would be the case for an ideal capacitor as expressed in equations (3) and (4). This point is more graphically illustrated in Figure A-11 where the measured capacitor voltage as a function of charge and discharge time during a 0.1 constant-current charge and discharge are shown compared to those predicted using the idealcapacitor model [equations (3) and (4)]. The value for the capacitance used in the ideal-capacitor model was $7.65 \mathrm{~F}$ and the value for $R_{c \text { and }}$ (the ESR value) was $0.748 \mathrm{ohm}$. These values for the capacitance and ESR were experimentally determined as discussed below. From Figure A-11, it is apparent that this capacitor deviates significantly from the ideal capacitor model in that it charges and discharges faster than the ideal-capacitor model at the early test times, but charges and discharges slower than the ideal-capacitor model at the later test times. This capacitor was tested using constant-current discharge values of $0.05 \mathrm{~A}, 0.10 \mathrm{~A}, 0.2 \mathrm{~A}$ and $0.40 \mathrm{~A}$. Figure A-12 shows the capacitor voltage as a function of discharge time. A constant-current charge at $0.1 \mathrm{~A}$ was used to initially charge the capacitor for each test. The discharge voltage is not a linear function of time illustrating the deviation from the ideal-capacitor model. The IR potential drop 
at the start of the test when the capacitor was at $1 \mathrm{~V}$ is also apparent. From these data, values were calculated for the capacitance [using equation (9)] and the equivalent series resistance, ESR [using equation (12)] as a function of the constant-current discharge current. The capacitance and ESR values are average values determined using the data from each of the three test cycles performed at each constant-current discharge current. These values are shown in Figures A-13 and A-14. The capacitance values are considerably lower than the value of $26 \mathrm{~F}$ as measured by Federal Fabrics-Fibers in their studies.

The results of the constant-power tests on this capacitor are shown in Figure A-15 which presents the discharge potential as a function of discharge time for constant-power discharges of 0.050 watt, 0.075 watt, 0.100 watt and 0.125 watts over the voltage range of $1 \mathrm{~V}$ to $0 \mathrm{~V}$ (the discharge voltage was actually limited to $0.005 \mathrm{~V}$ for these tests). Values of the specific energy and specific power of the capacitor were calculated using equation (13) over the voltage range of $1 \mathrm{~V}$ to $0.5 \mathrm{~V}$. These values are plotted in Figure A-16.

Capacitor \#P20-032: Constant-current tests were run on this capacitor using a $0.1 \mathrm{~A}$ constant-current charge over the voltage range of $0 \mathrm{~V}$ to $1 \mathrm{~V}$, followed by a 10 seconds hold at 1 $\mathrm{V}$ and then various constant-current discharges ranging from $0.05 \mathrm{~A}$ to $0.80 \mathrm{~A}$ to $0 \mathrm{~V}$ followed by a 10 second hold at $0 \mathrm{~V}$ for 10 seconds. An example of a three-cycle test sequence is shown in Figure A-17 for 0.1 A constant-current charges and discharges. Comparing this figure with Figure A-10, it is apparent that capacitor \#P20-032 more closely approaches the behavior expected of an ideal capacitor, in that the voltage for the charge and discharge portions are more nearly symmetric and the voltage is a more linear function of time than was observed for capacitor \#P20-029. These observation are more fully illustrated in Figure A-18 where the experimental 0.1 A constant-current charge and discharge data is compared with those expected based on the ideal-capacitor models expressed by equations (3) and (4). The value for the capacitance used in these equations was $12.82 \mathrm{~F}$; the value for $R_{c \text { and } d}$ was $0.329 \mathrm{ohms}$, both of which were determined experimentally using equations (9) and (12) respectively. The capacitor is observed to charge and discharge more rapidly than an ideal capacitor at short test times, and to charge and discharge less rapidly at the longer test times.

Figure A-19 shows the experimental discharge potential as a function of discharge time for constant-current discharges of $0.05 \mathrm{~A}, 0.10 \mathrm{~A}, 0.20 \mathrm{~A}, 0.40 \mathrm{~A}$ and $0.80 \mathrm{~A}$. Using equations (9) and (12) the values for the capacitance and the equivalent series resistance as a function of constant-current discharge current were calculated. These values are plotted in Figures A-13 and A-14, respectively. As is shown the capacitance varied from $13.2 \mathrm{~F}$ to $8.0 \mathrm{~F}$, and the ESR values ranged from $0.501 \mathrm{ohms}$ to $0.241 \mathrm{ohms}$ for the constant-current discharge current range studied. The measured capacitance values are close to the $14 \mathrm{~F}$ as reported by Federal Fabrics-Fibers in 
their studies.

Constant-power tests were conducted using a 0.1 A constant-current charge from $0 \mathrm{~V}$ to $1 \mathrm{~V}$, and constant-power discharge to $0.005 \mathrm{~V}$ varying from 0.050 watt to 0.200 watt, repeating the test cycle three times. The experimental discharge potential as a function of constant-power discharge time is presented in Figure A-20 for the five constant-power discharge powers used: 0.050 watt, 0.100 watt, 0.200 watt, 0.250 watt and 0.300 watt. From these data the specific energy and specific power were calculated using equation (13) over the voltage range of $1 \mathrm{~V}$ to $0.5 \mathrm{~V}$. These values are plotted in Figure A-16.

Capacitor \#P20-033: Constant-current tests were conducted first on this capacitor. The capacitor potential as a function of test time for a three-cycle constant-current test using a $0.1 \mathrm{~A}$ charge and discharge over the voltage range of $0 \mathrm{~V}$ to $1 \mathrm{~V}$ is shown in Figure A-21. The charge and discharge potential curves are fairly symmetrical and somewhat linear with test time. Figure A-22 examines these measurements in comparison with the charge and discharge potential time dependence as calculated using the ideal-capacitor model [equations (3) and (4)]. The capacitance value used in the equations was $7.69 \mathrm{~F}$ and $R_{c}$ and $d$ was $0.224 \mathrm{ohms}$; these values were determined experimentally from the data presented in Figure A-21. Figure A-22 shows that the capacitor charges faster at smaller charge times than an ideal-capacitor, but charges slower at the longer charge times. The slope of the constant-current discharge potential is larger than predicted by the ideal-capacitor model at times less than 30 seconds, but is greater at the longer times.

Figure A-23 shows the experimental discharge potential as a function of discharge time for constant-current discharges of $0.05 \mathrm{~A}, 0.10 \mathrm{~A}, 0.20 \mathrm{~A}, 0.40 \mathrm{~A}$ and $0.80 \mathrm{~A}$. Using equations (9) and (12) the values for the capacitance and the equivalent series resistance as a function of constant-current discharge current were calculated. These values are plotted in Figures A-13 and A-14, respectively. As shown in these figures, the capacitance varied from $7.93 \mathrm{~F}$ to $6.30 \mathrm{~F}$, and the ESR values ranged from $0.346 \mathrm{ohms}$ to $0.107 \mathrm{ohms}$ for the constant-current discharge current range studied. The capacitance values measured are close to the $7.7 \mathrm{~F}$ as reported by Federal Fabrics-Fibers in their studies.

Constant-power tests were conducted using a 0.1 A constant-current charge from $0 \mathrm{~V}$ to $1 \mathrm{~V}$, followed by constant-power discharges to $0.005 \mathrm{~V}$ at levels from 0.050 watt to 0.200 watt, repeating the same cycle three times. The experimental discharge potential as a function of constant-power discharge time is presented in Figure A-24 for the five constant-power discharge powers used: 0.050 watt, 0.075 watt, 0.100 watt, 0.150 watt and 0.200 watt. From these data the specific energy and specific power were calculated using equation (13) over the voltage range of $1 \mathrm{~V}$ to $0.5 \mathrm{~V}$. These values are plotted in Figure A-16. 


\section{SUMMARY}

Two sets of capacitors, Set \#1(one capacitor) and Set \#2 (three capacitors), supplied by Federal Fabrics-Fibers, that were based on an experimental bipolar or monopolar Z-axis carbon electrode design that used $\mathrm{Ni}$ and a proprietary plastic current collector, a polypropylene separator and casing, with a $\mathrm{KOH}$ containing aqueous electrolyte in an un-optimized package were tested using constant-current and constant-power test conditions.

For capacitor Set \#1 the constant-current tests allowed determination of the capacitance and equivalent series resistance (ESR) of the capacitor. A voltage range of $0 \mathrm{~V}$ to $1 \mathrm{~V}$ was used in the tests. The capacitor displayed deviations from an ideal capacitor behavior in that the capacitor voltage during constant-current charging and discharging was not a linear function of the charge or discharge time. The measured capacitance varied from $10.5 \mathrm{~F}$ at a $0.1 \mathrm{~A}$ constantcurrent discharge to $6.2 \mathrm{~F}$ at $1.0 \mathrm{~A}$. The equivalent series resistance also varied with the discharge current during the constant-current test and ranged from 149.6 milliohms at $0.1 \mathrm{~A}$ to 32.4 milliohms at 1.0 A. The specific energies and specific powers of the capacitor, as determined from the constant-current tests, ranged from $3.51 \times 10-2 \mathrm{~W} \cdot \mathrm{h} / \mathrm{kg}$ at $3.35 \times 10^{-4} \mathrm{~W} / \mathrm{kg}$ to $2.49 \times 10^{-2} \mathrm{~W} \cdot \mathrm{h} / \mathrm{kg}$ at $3.35 \times 10^{-3} \mathrm{~W} / \mathrm{kg}$. A constant-power test at 0.0418 watt for a voltage range of $1 \mathrm{~V}$ to $0 \mathrm{~V}$ allowed a determination of its specific energy ( $1 \mathrm{~V}$ to $0.5 \mathrm{~V}$ discharge range) to be equal to $1.75 \times 10^{-2} \mathrm{~W} \cdot \mathrm{h} / \mathrm{kg}$ at $1.01 \mathrm{~W} / \mathrm{kg}$. An anomalous constant-power test caused an alteration in the physical/chemical properties of the capacitor which reduced its capacitance, increased its ESR, and decreased its specific energy density thus preventing further, reliable testing of the capacitor.

The three capacitors that comprised Set \#2 (\#P20-029, \#P20-032, and \#P20-033) were also based on an experimental bipolar or monopolar $\mathrm{Z}$-axis carbon electrode design that used $\mathrm{Ni}$ and a proprietary current collector material, a polypropylene separator and casing with a $\mathrm{KOH}$ containing aqueous electrolyte in an un-optimized package. These capacitors were also tested using constant-current and constant-power test conditions. From the constant-current tests the capacitance and equivalent series resistance (ESR) of the capacitors were determined as a function of the constant-current discharge value. A voltage range of $0 \mathrm{~V}$ to $1 \mathrm{~V}$ was used in these 
tests in conjunction with a constant-current charge current of $0.1 \mathrm{~A}$. The capacitors displayed deviations from an ideal-capacitor behavior in that the capacitors' voltage during constantcurrent charging and discharging was not a linear function of the charge or discharge time. The equivalent series resistance also varied with the discharge current during the constant-current test. Specific energies and powers of the capacitors were determined from the constant-power tests. The best capacitor, \#P20-032, had values for the specific energy and power that ranged from $2.56 \times 10^{-2} \mathrm{~W} \cdot \mathrm{h} / \mathrm{kg}$ at $1.37 \mathrm{~W} / \mathrm{kg}$ to $1.31 \times 10^{-2} \mathrm{~W} \cdot \mathrm{h} / \mathrm{kg}$ at $8.19 \mathrm{~W} / \mathrm{kg}$.

The overall power and energy performance (Figure A-5 and B-7) of these early devices was somewhat lower than expected even compared to other aqueous-based electrochemical capacitors tested at the INEEL. ${ }^{3-69}$ This performance is in part a result of immature packaging that significantly contributed to the weight and volume occupied by non-active materials. A second technological barrier at issue with this technology is Federal Fabrics-Fibers' continued efforts to develop a lighter, cheaper non-metallic current collection system that fully utilizes the theoretical advantages of the Z-axis fiber electrodes used in these devices. The fact that the ESR values are still higher than desired indicates that this is still an issue.

The entire planned test program has not been completed, and some remaining late deliverables have not yet been evaluated. In addition to the cells reported herein, devices based on this carbon technology and rated at $10 \mathrm{~V}$ will be tested later to characterize their performance. The results of that testing, in addition to any additional single-cell testing, will be reported in a follow-on report. It is also now understood that carbon-based, double-layer capacitors using aqueous electrolytes will not exhibit the minimum performance needed to meet PNGV goals for hybrid propulsion systems. ${ }^{7}$ Similar double-layer devices tested using non-aqueous electrolytes still fall short of PNGV goals. ${ }^{6}$ At any rate, the true potential of the Federal Fabrics-Fibers Zaxis electrode design has not been fully realized, and the authors believe that there are still many potential applications for carbon-based electrochemical capacitors. 


\section{REFERENCES}

1. F. W. A. H. Geurts and R. C. McDonald, "Activated Carbon Fiber Arrays for DoubleLayer Supercapacitor Electrodes," Proceedings of the 37th Power Sources Conference, Cherry Hill, NJ, June 17-20, 1996, p. 128.

2. F. W. A. H. Geurts and Z. Horovitz, "Carbons for Supercapacitors," Proceedings of the 6th International Seminar on Double Layer Capacitors and Similar Energy Storage Devices, Volume 6, December 9-11, 1996.

3. T. C. Murphy and W. E. Kramer, "U. S. Department of Energy Ultracapacitor Development Program for Load Leveling Electric Vehicle Propulsion Systems," Proceedings of the 4th International Seminar on Double Layer Capacitors and Similar Energy Storage Devices, Volume 4, December 12-14, 1994.

4. T. C. Murphy, R. B. Wright, and R. A. Sutula, "Performance of Electrochemical Capacitors," Proceedings of the 6th International Seminar on Double Layer Capacitors and Similar Energy Storage Devices, Volume 6, December 9-11, 1996.

5. T. Murphy and P. B. Davis, "Electrochemical Capacitors," Proceedings of the Symposium on Electrochemical Capacitors , F. M. Delnick and M. Tomkiewicz, eds., Volume 95-29 (The Electrochemical Society, Inc., Pennington, NJ, 1996) p. 269.

6. T. C. Murphy, R. B. Wright, and R. A. Sutula, "U. S. Department of Energy Electrochemical Capacitor Development and Testing Activities," Proceedings of the Symposium on Electrochemical Capacitors II, F. M. Delnick, D. Ingersoll, X. Andrieu and K. Naoi, eds., Volume 96-25 (The Electrochemical Society, Inc., Pennington, NJ, 1997), p. 258.

7. R. A. Sutula, "The Department of Energy's High-Power Energy Storage Programs," in Preprints of the Annual Automotive Technology Development Customers' Coordination - Meeting, Volume I Oral Presentations, October 28-November 1, 1996.

8. J. R. Miller and A. F. Burke, "Electric Vehicle Capacitor Test Procedures Manual, Revision 0," published October 1994, Report DOE/ID-10491.

9. A. F. Burke, "Electrochemical Capacitors for Electric and Hybrid Vehicles - The DOE Program and the Status of the Technology - 1993," published October 1994, Report INEL-94/0036. 


\section{APPENDIX A}

\section{GRAPHIC FIGURES}

FOR

FEDERAL FABRICS-FIBERS CAPACITORS SET \#1 and \#2

( Nos. P18-196, P20-029, P20-032, and P20-033) 
A-2 


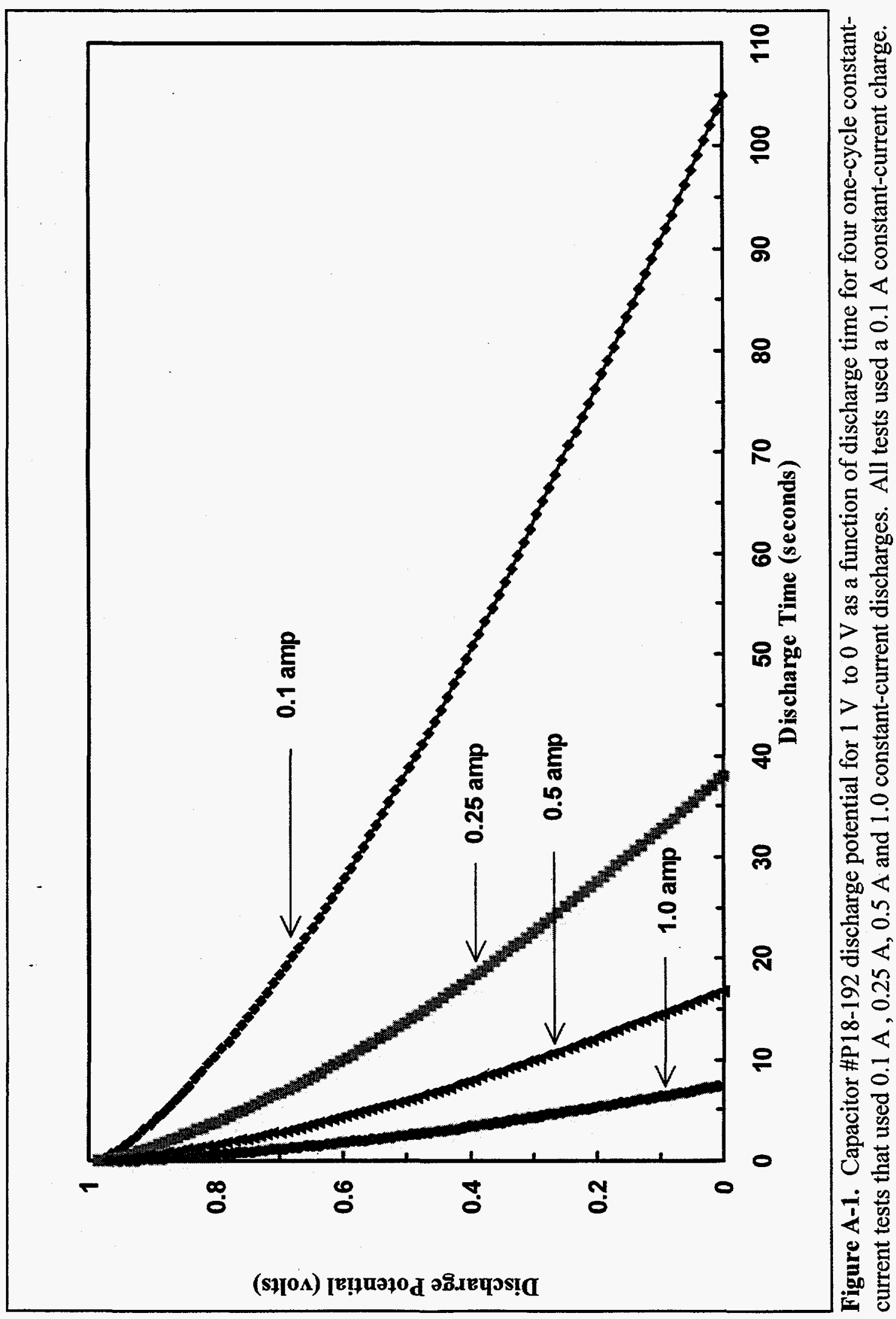




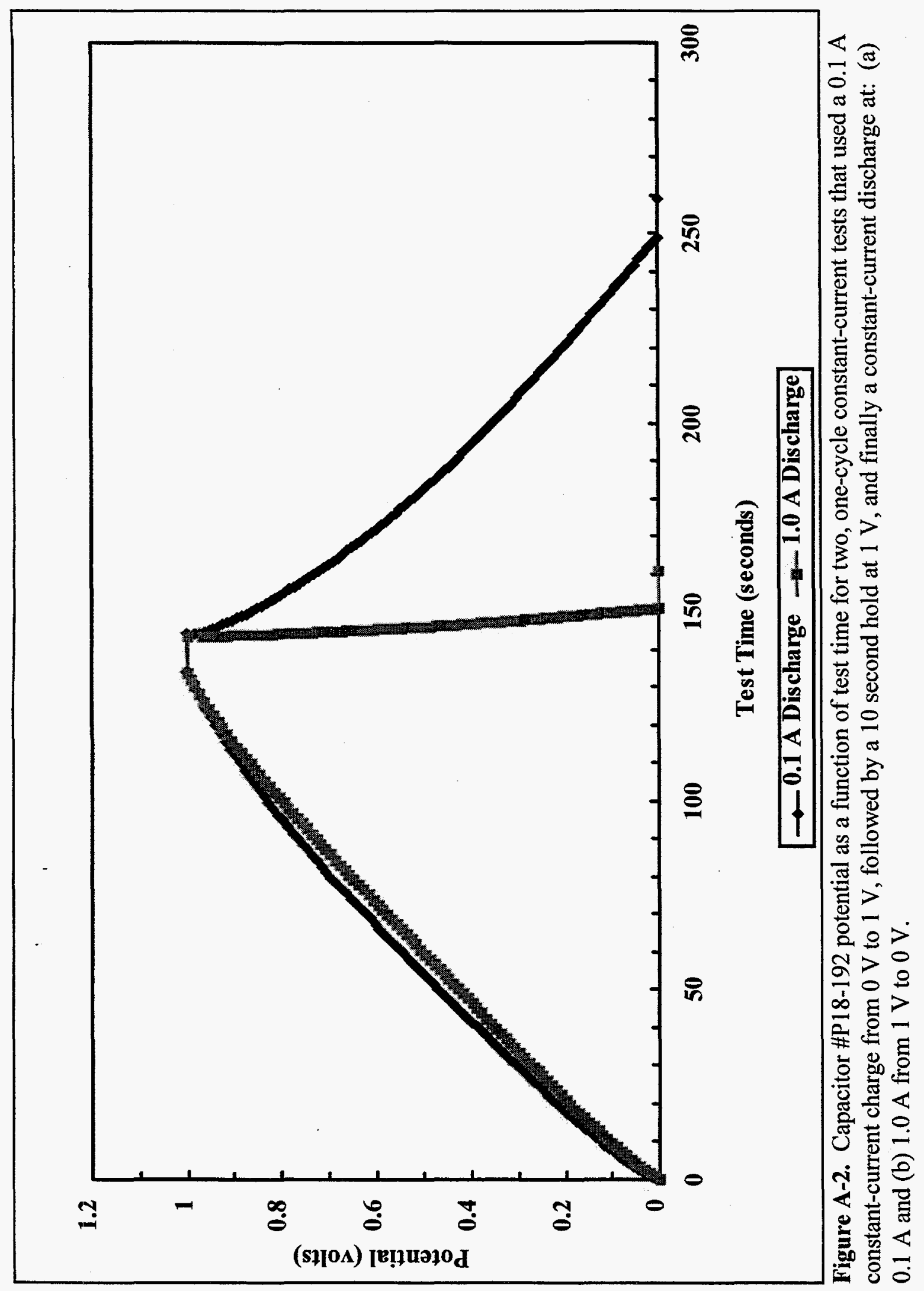




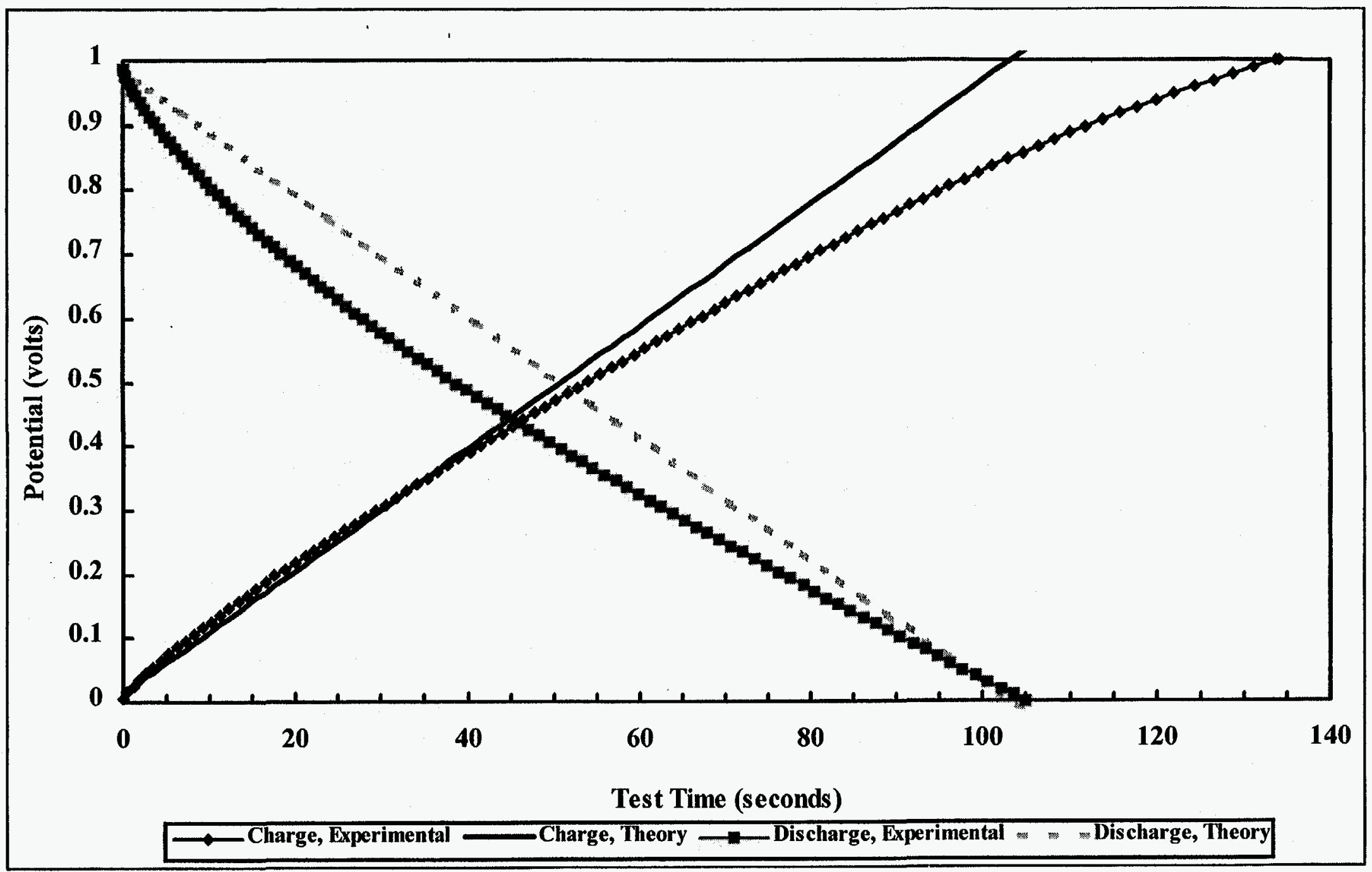

Figure A-3. Experimental and calculation of the discharge potential (using the theoretical ideal-capacitor model) as a function of discharge time for a 0.1 A constant-current charge/discharge for Capacitor \#P18-192. 


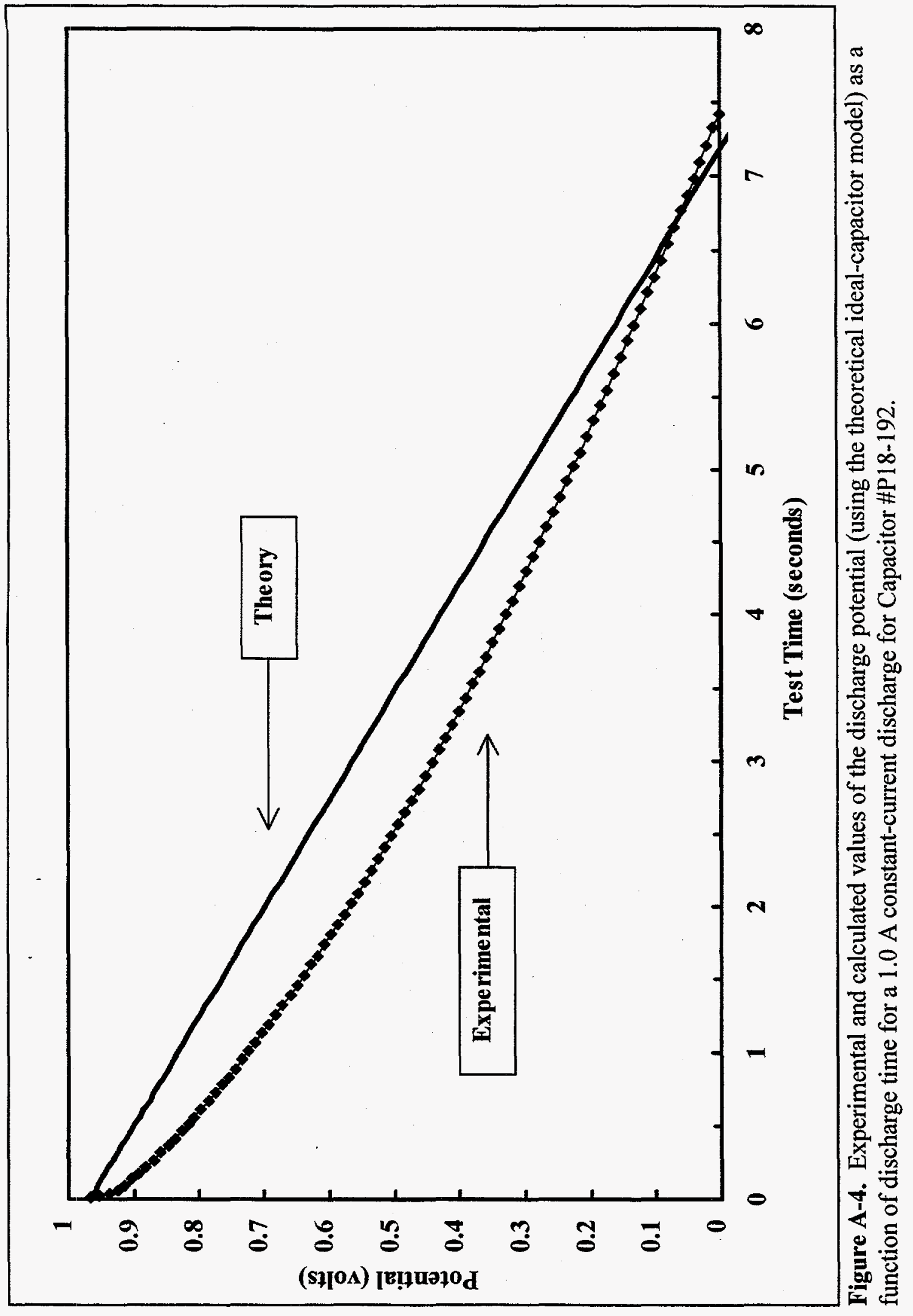




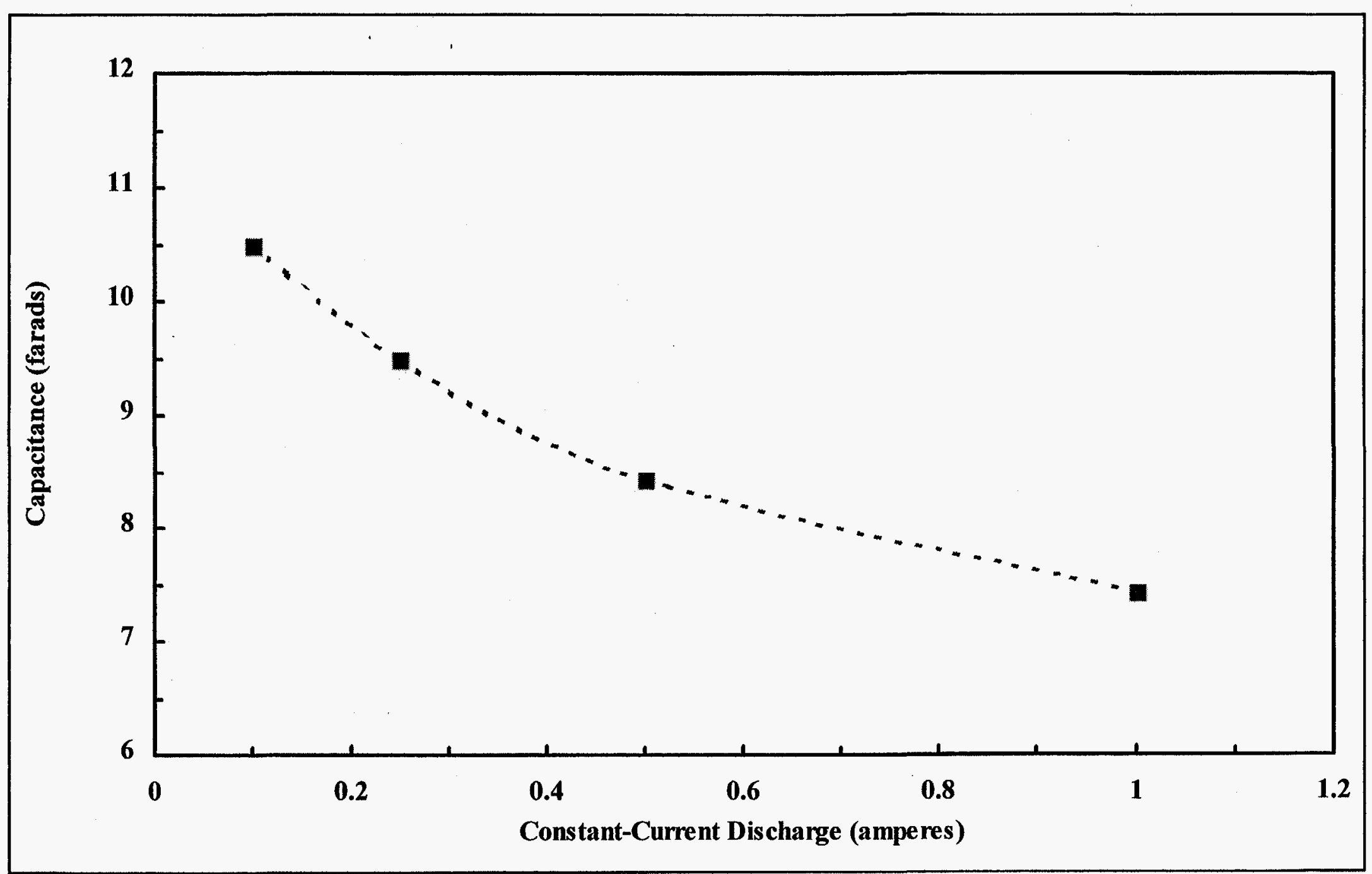

Figure A-5. Measured capacitance (determined from constant-current tests) as a function of constant-current discharge current for capacitor \#P18-192. 


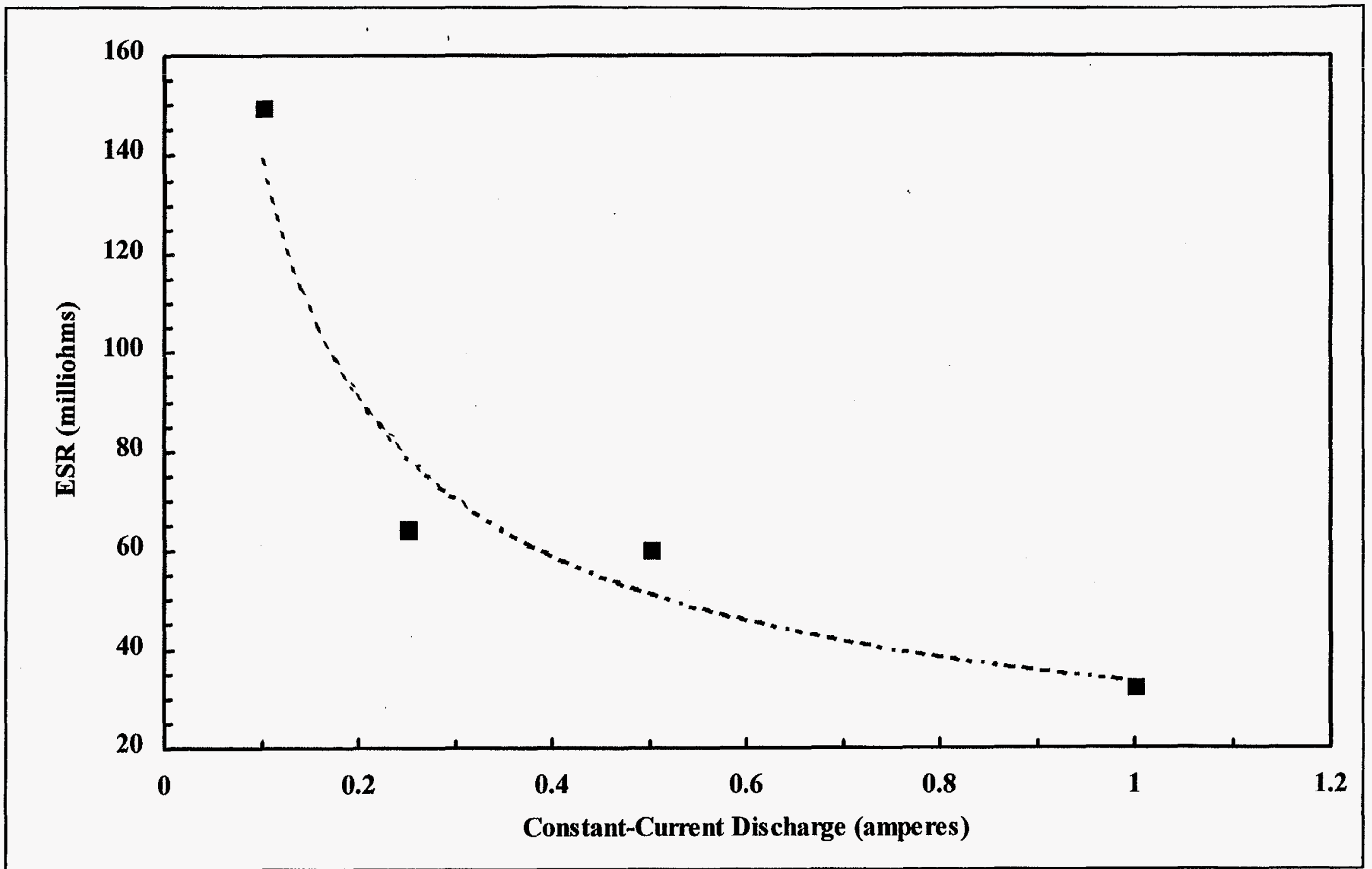

Figure A-6. Equivalent Series Resistance (ESR) determined from the constant-current tests as a function of constant-current discharge current for capacitor \#P18-192. 


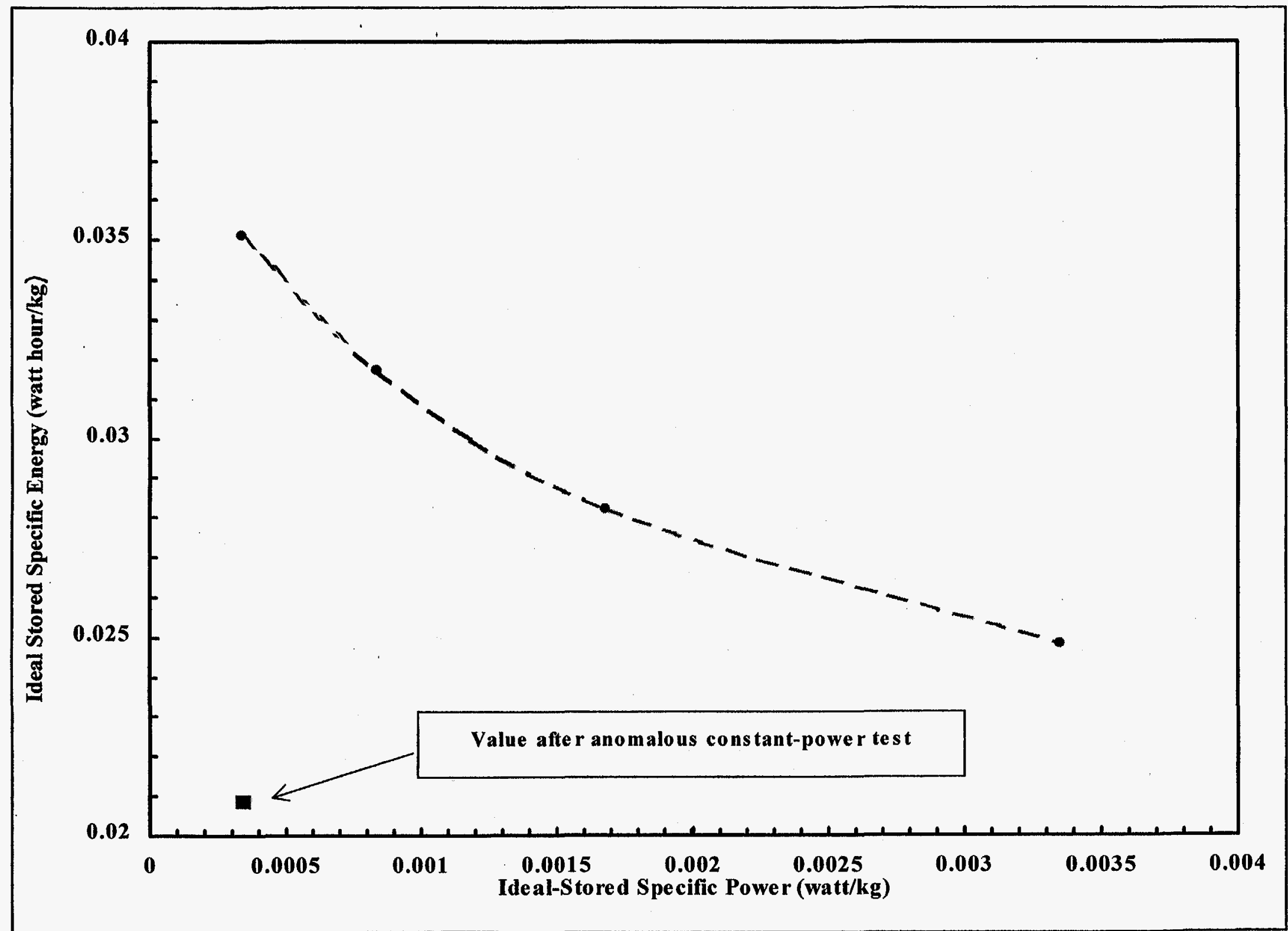

Figure A-7. Ideal-stored (i.e., working) specific energy as a function of ideal-stored (i.e., working) specific power as determined from the constant-current tests. The ideal-stored specific energy as measured from a $0.1 \mathrm{~A}$ constant-current test following an anomalous constant-power test is also shown (refer to text for details) for capacitor \#P18-192. 


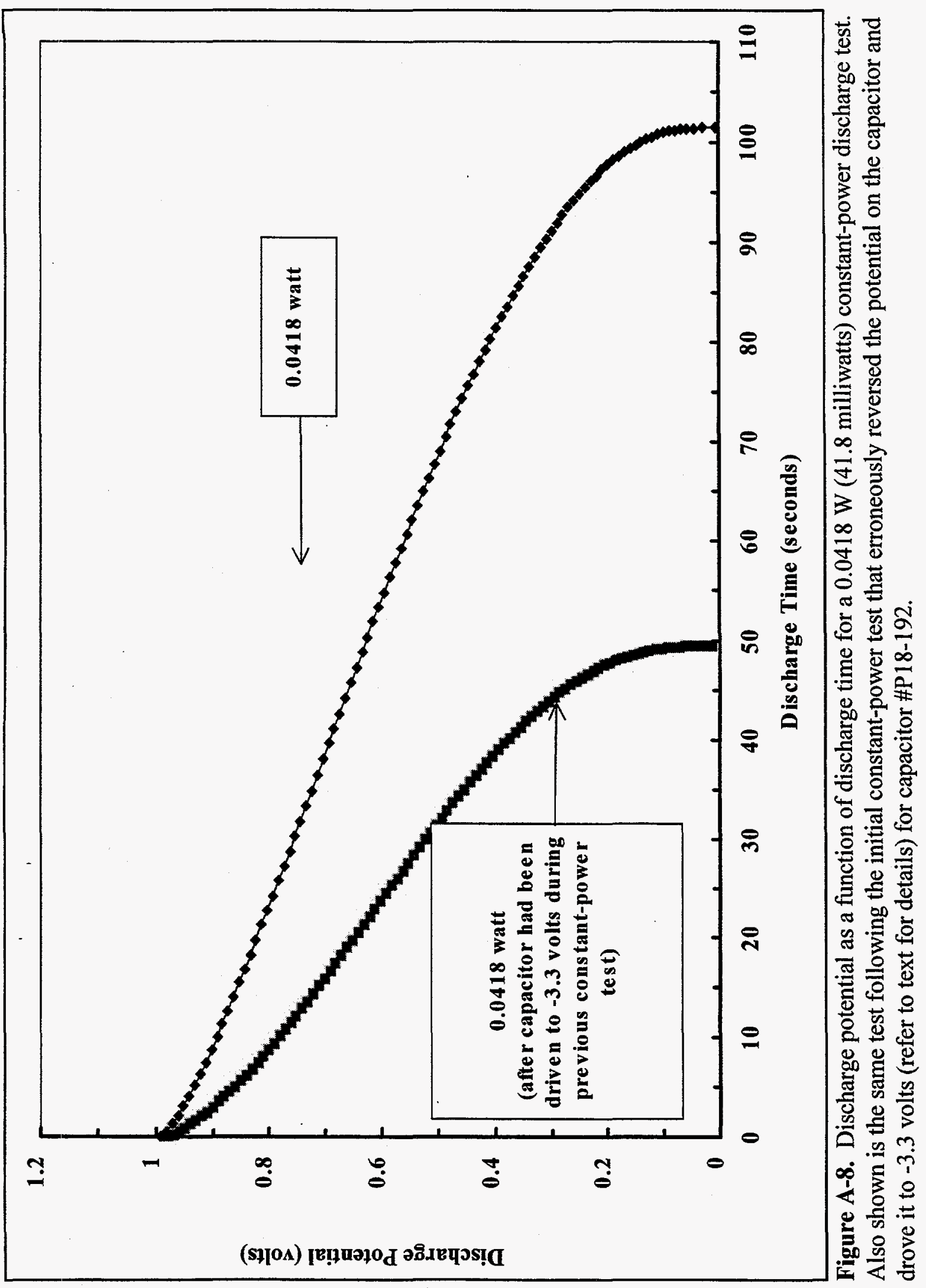




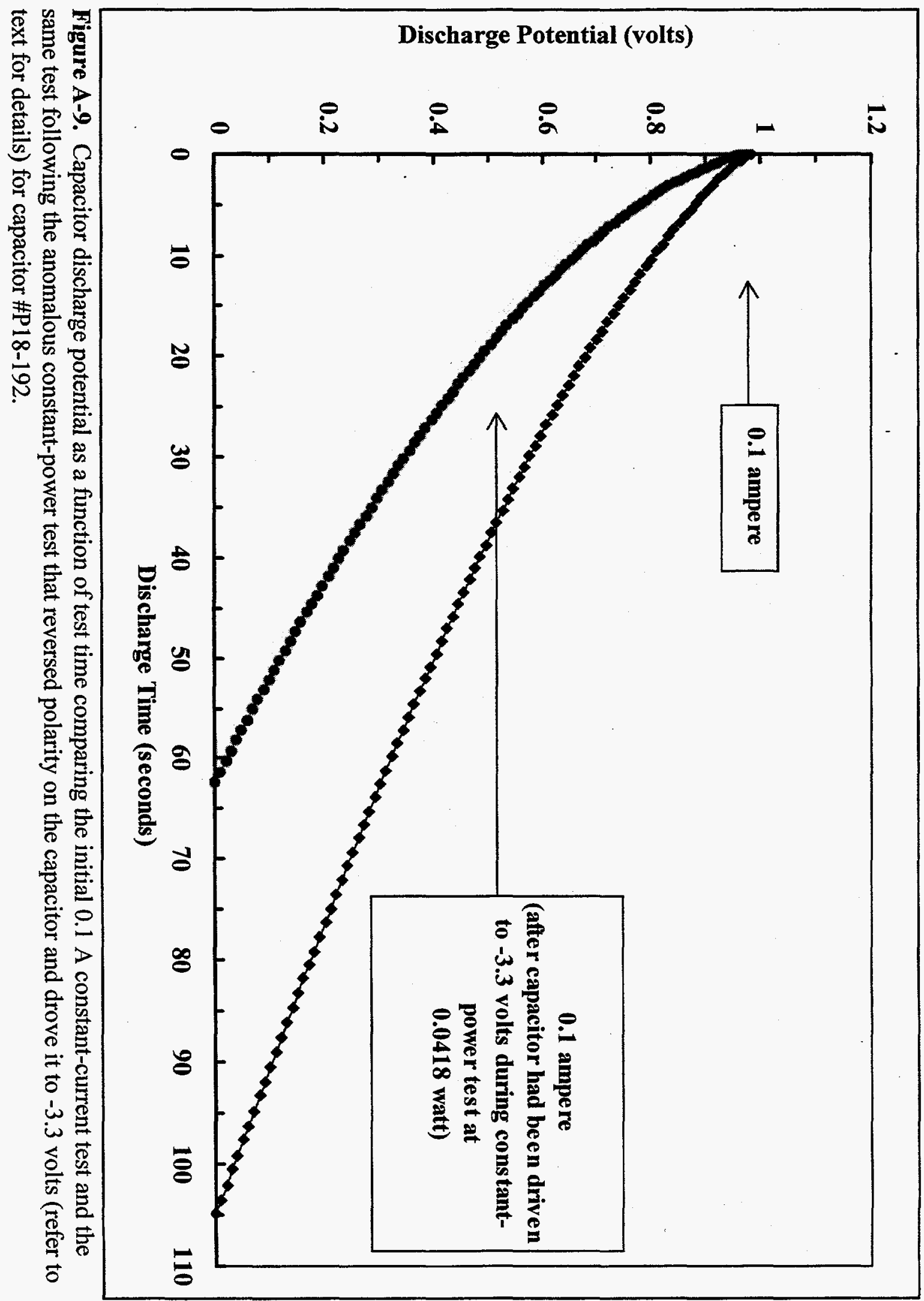




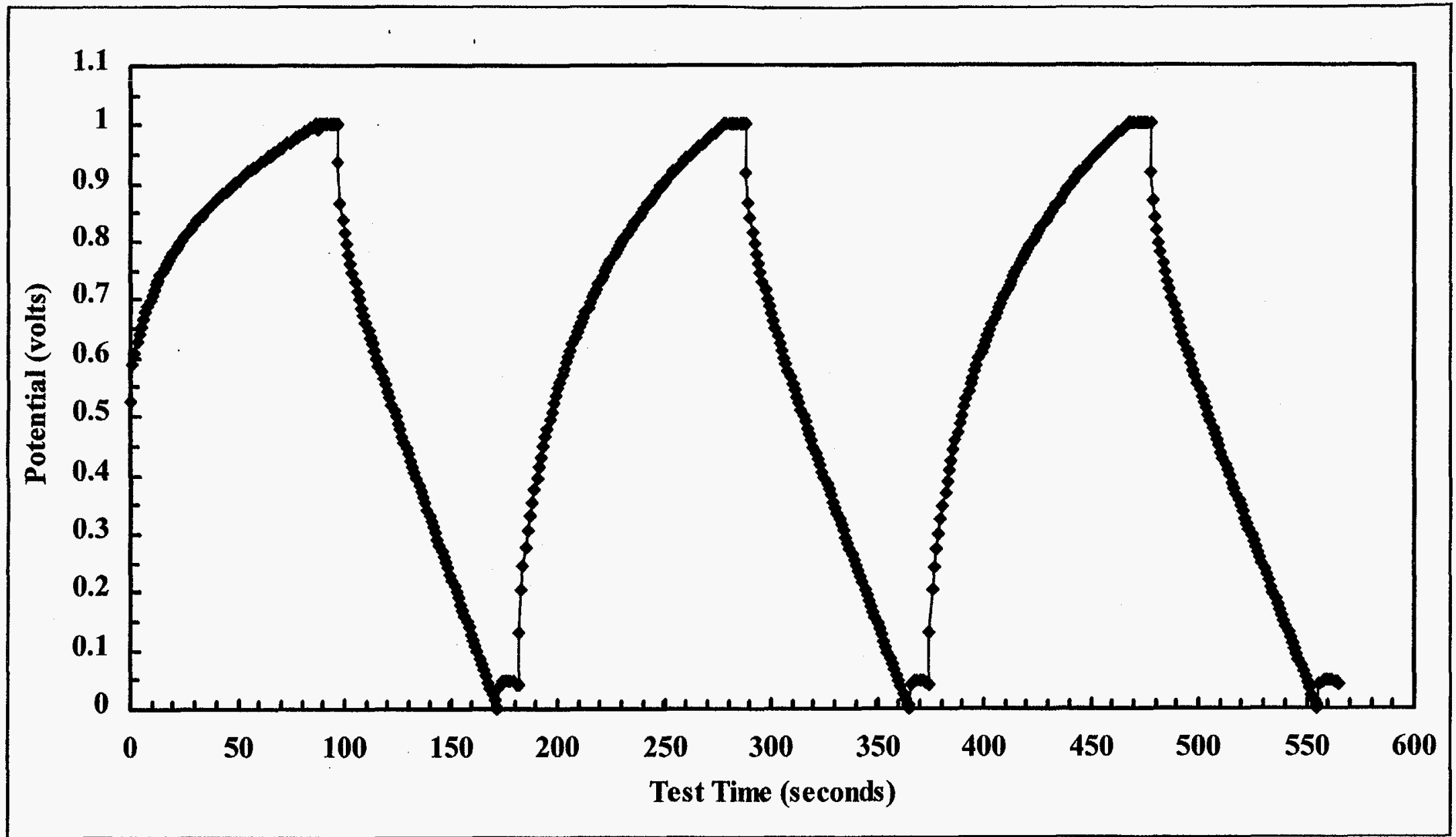

Figure A-10. Capacitor potential as a function of test time for a three-cycle constant-current test on capacitor \#P20-029 that used a 0.1 A constant-current charge from 0 to $1 \mathrm{~V}$, followed by a 10 second hold at $1 \mathrm{~V}$, and finally a constant-current discharge at $0.1 \mathrm{~A}$ from 3 to $0 \mathrm{~V}$. 


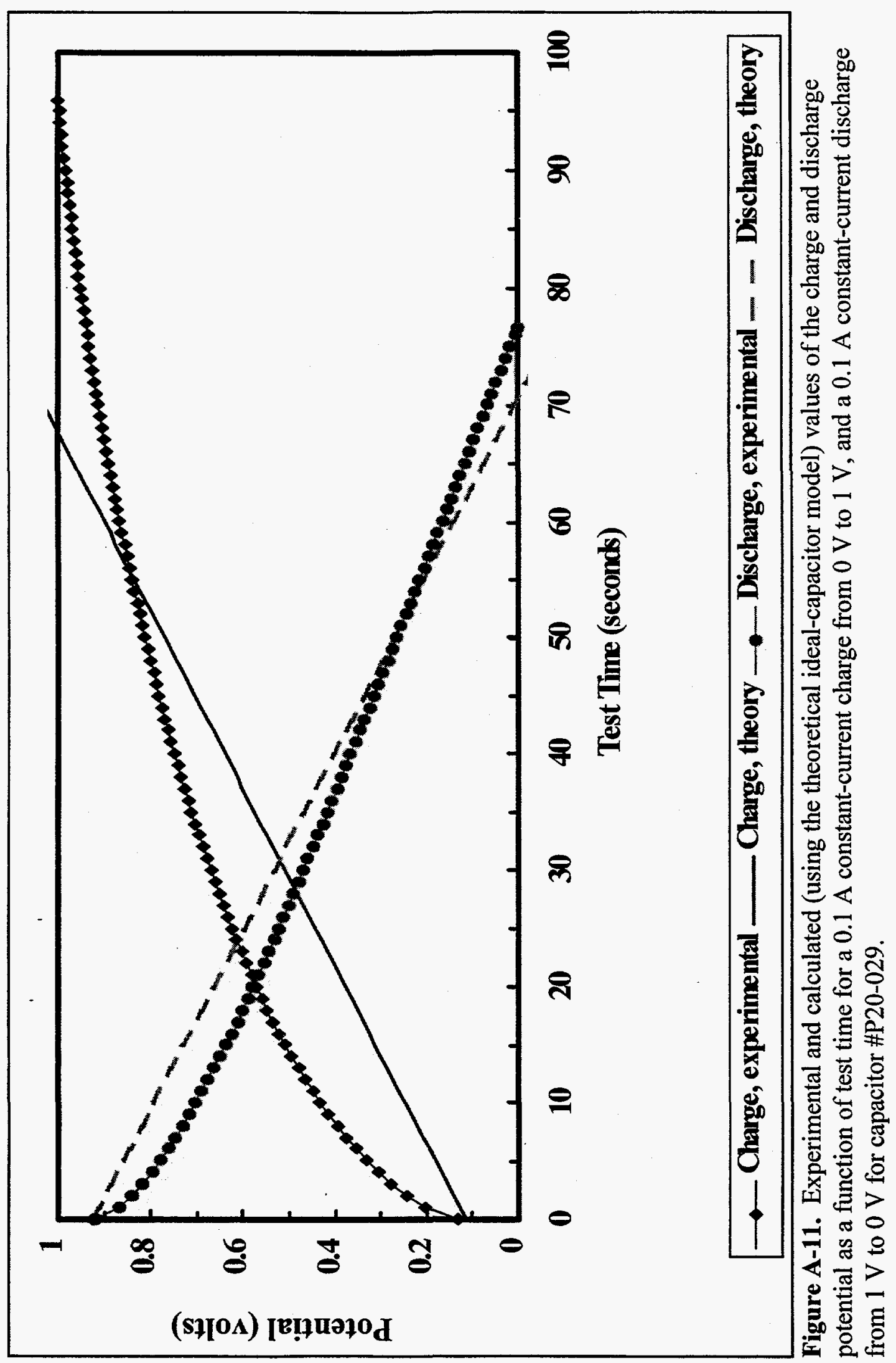




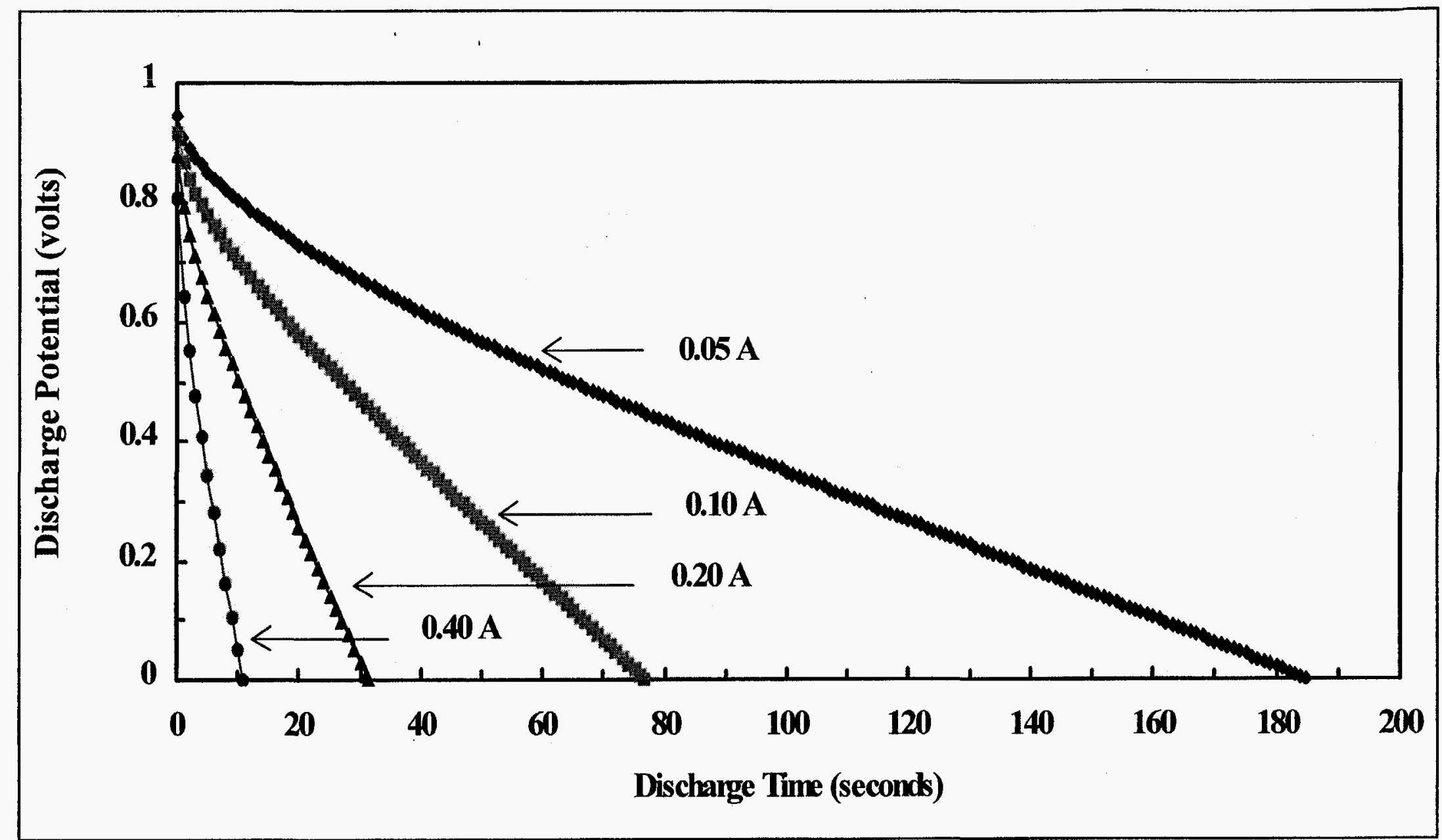

Figure A-12. Capacitor discharge potential for capacitor \#P20-029 for $1 \mathrm{~V}$ to $0 \mathrm{~V}$ as a function of discharge time for constantcurrent tests that used $0.05 \mathrm{~A}, 0.10 \mathrm{~A}, 0.20 \mathrm{~A}$, and $0.40 \mathrm{~A}$ constant-current discharges. All tests used a $0.1 \mathrm{~A}$ constant-current charge. 


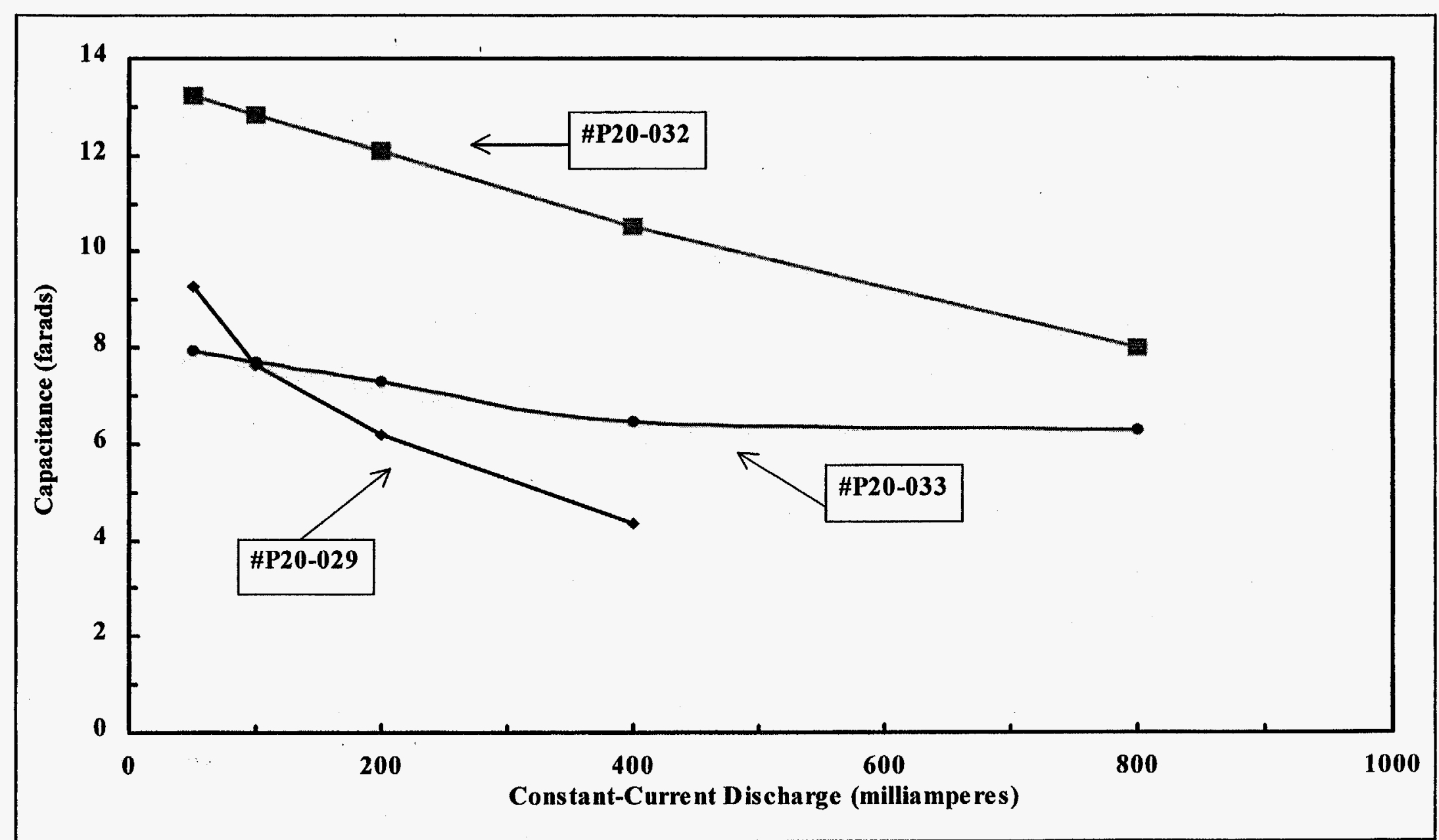

Figure A-13. Measured capacitance (determined from constant-current tests) as a function of constant-current discharge current for the three capacitors under test. 


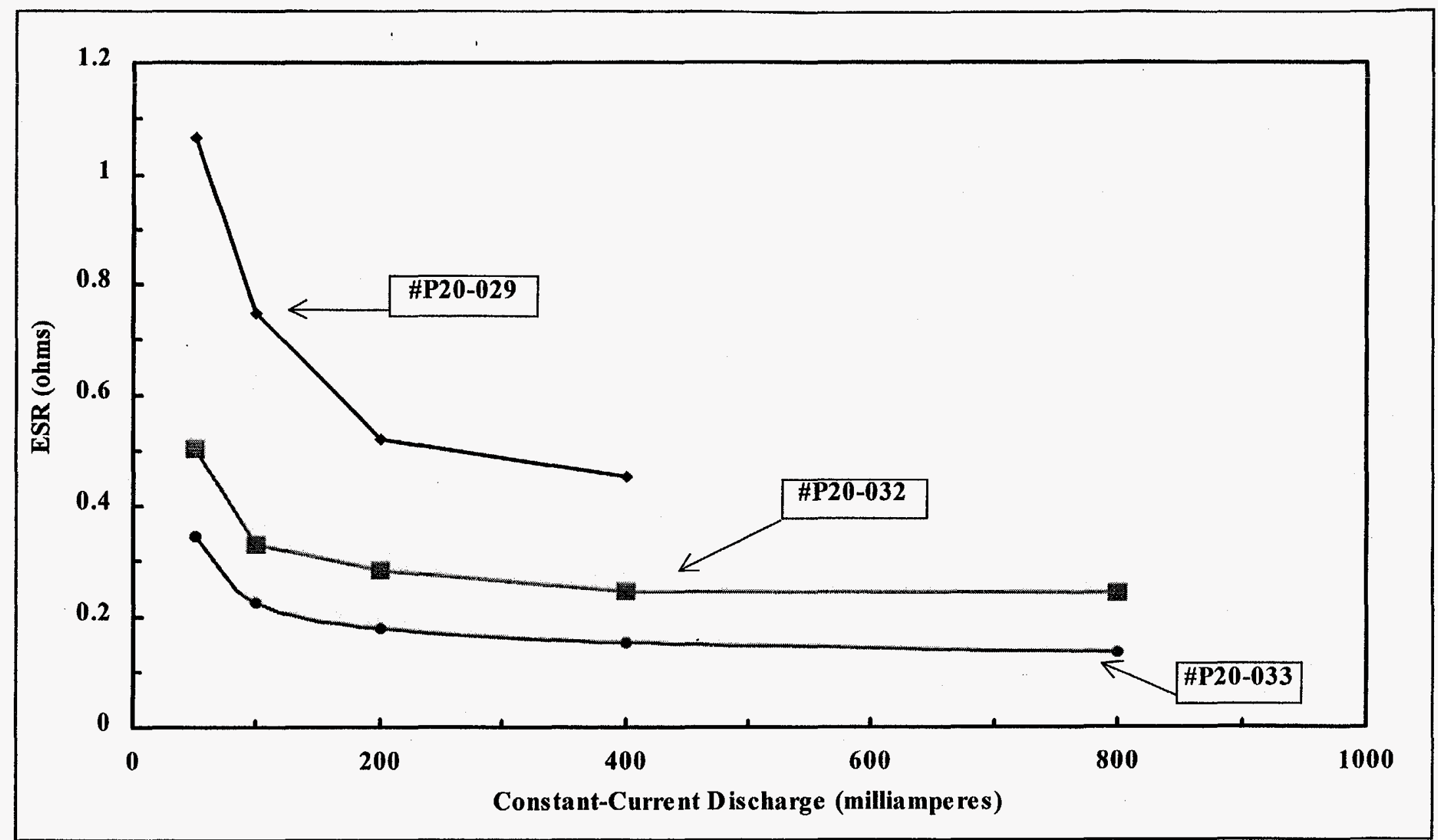

Figure A-14. Equivalent Series Resistance, ESR, determined from the constant-current tests, as a function of constant-current discharge current for the three capacitors of Set $\# 2$. 


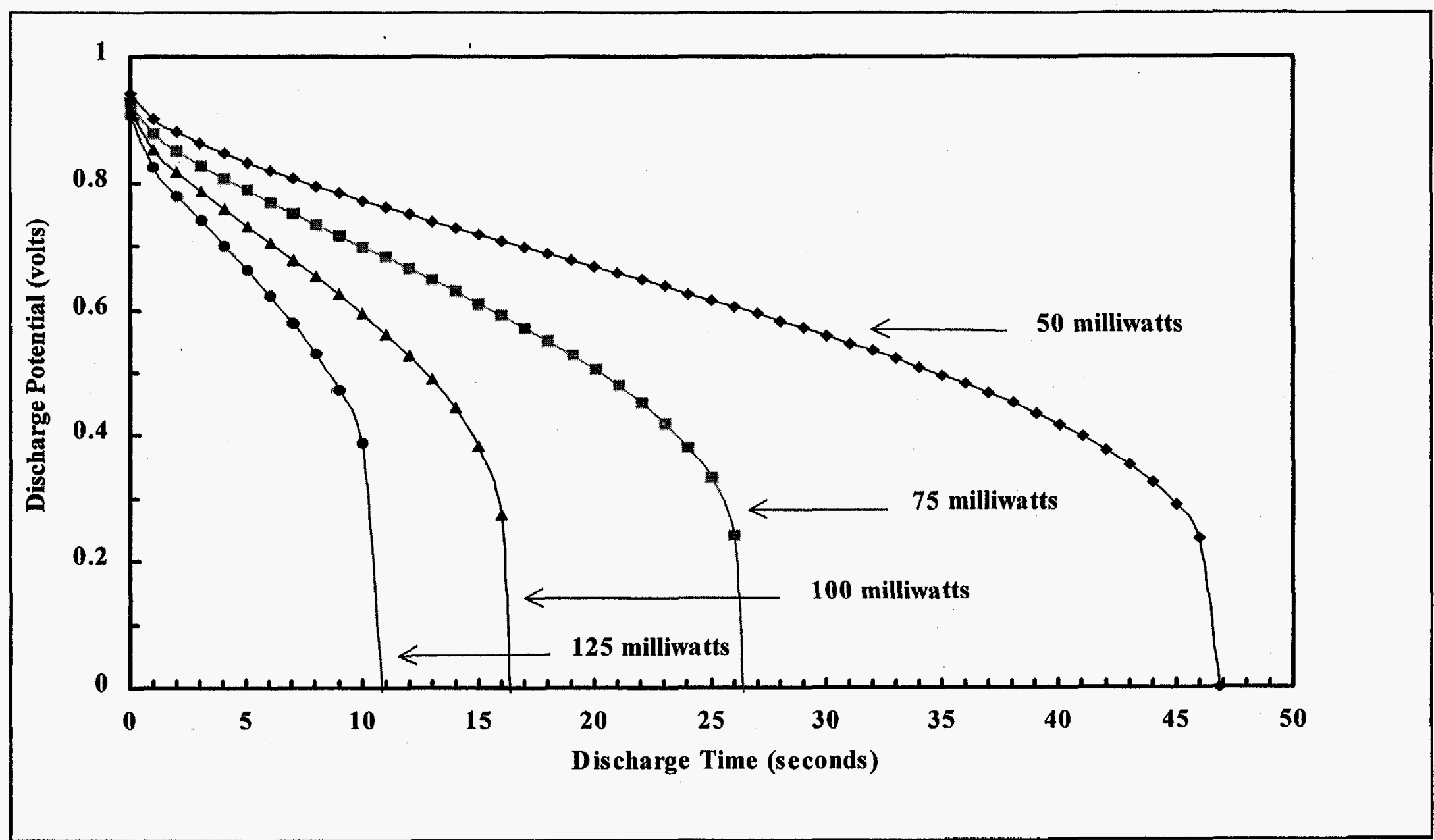

Figure A-15. Discharge potential as a function of discharge time for constant-power discharge tests at 50 milliwatts, 75 milliwatts, 100 milliwatts and 125 milliwatts for capacitor \#P20-029. 


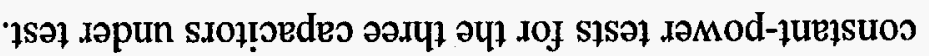

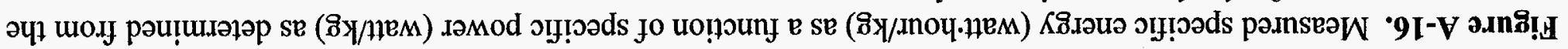

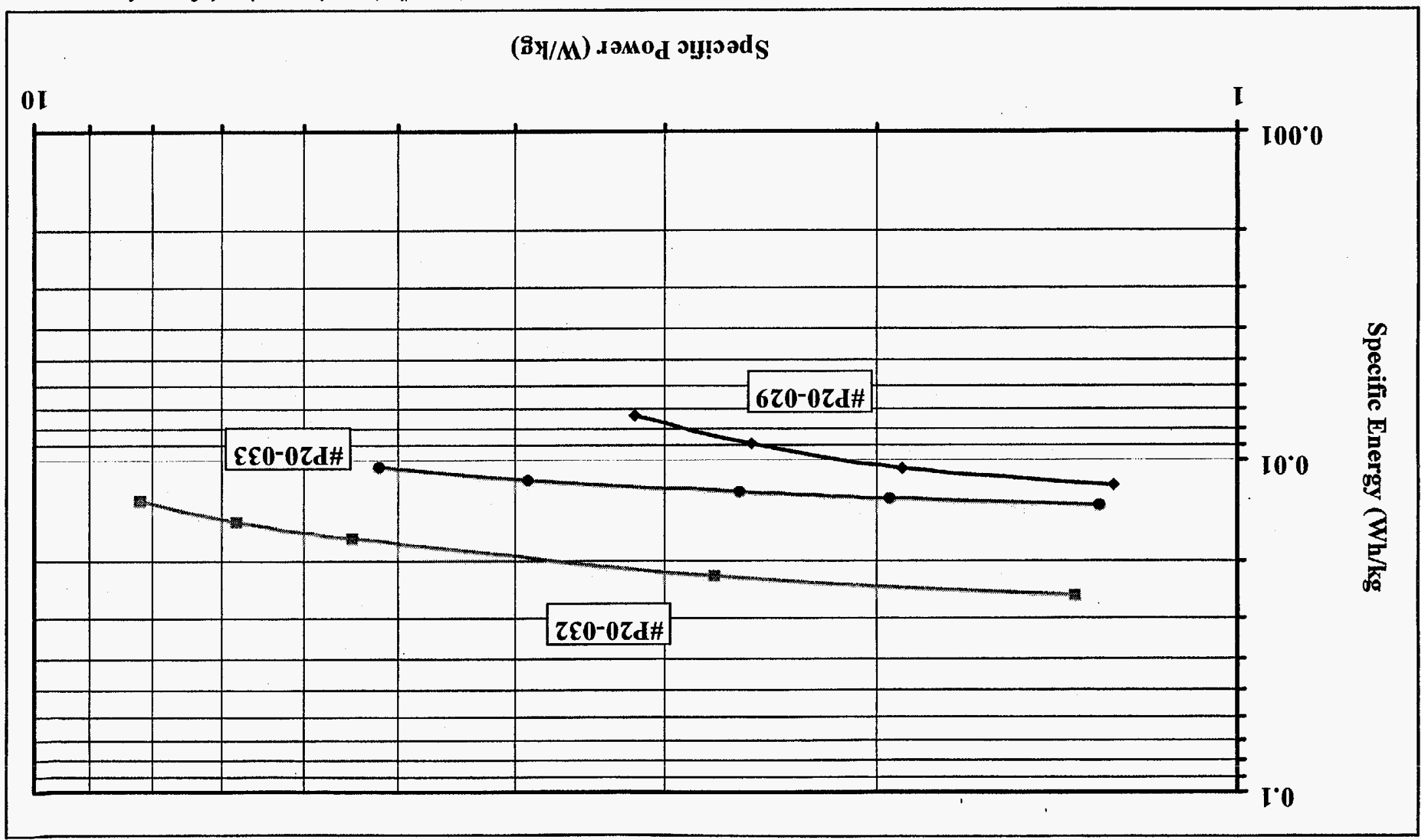




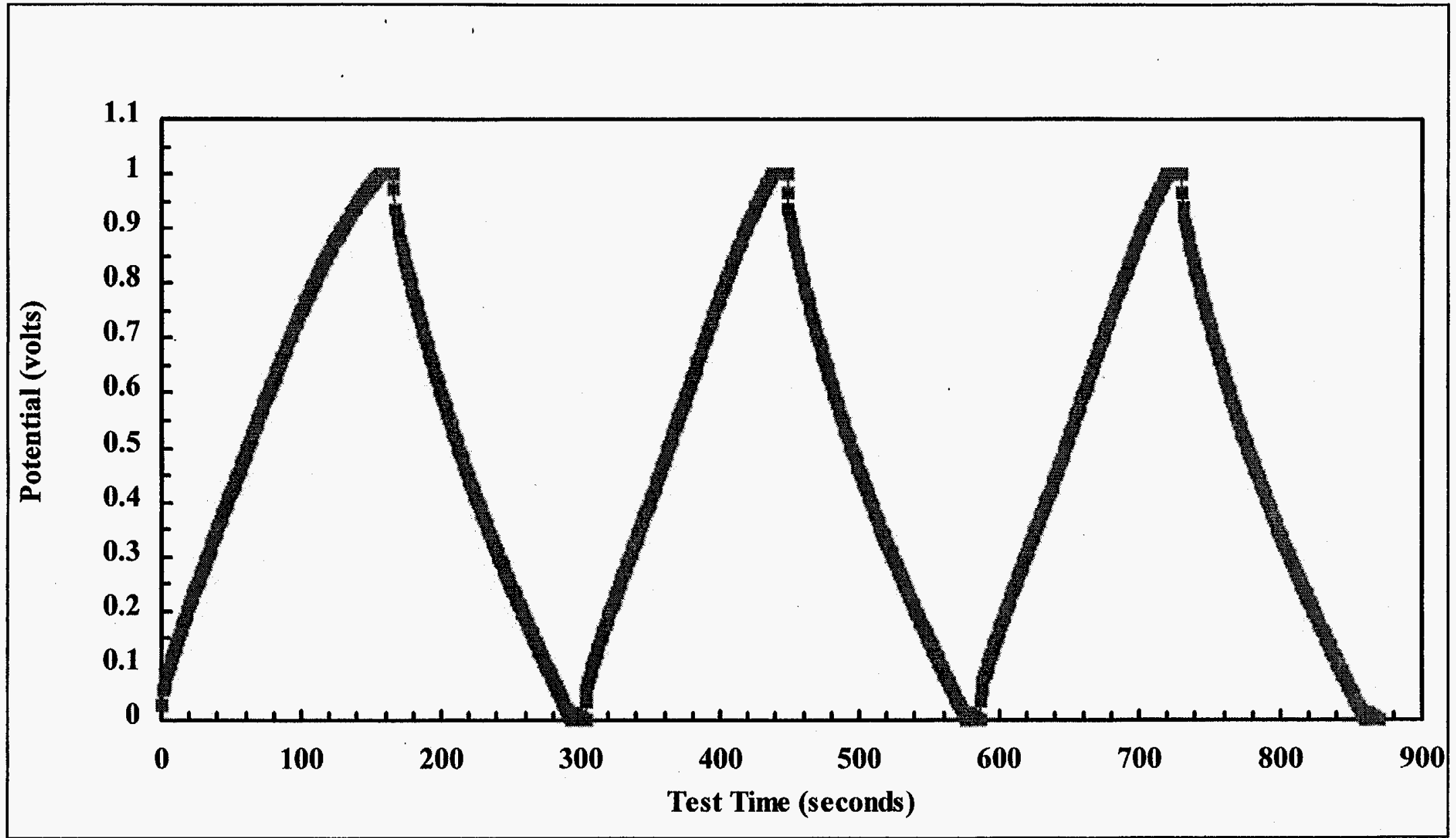

Figure A-17. Capacitor potential as a function of test time for a three-cycle constant-current test on capacitor \#P20-032 that used a 0.1 A constant-current charge from $0 \mathrm{~V}$ to $1 \mathrm{~V}$, followed by a 10 second hold at $1 \mathrm{~V}$, followed by a constant-current discharge at $0.1 \mathrm{~A}$ from $1 \mathrm{~V}$ to $0 \mathrm{~V}$, and finally a 10 second hold at $0 \mathrm{~V}$. 


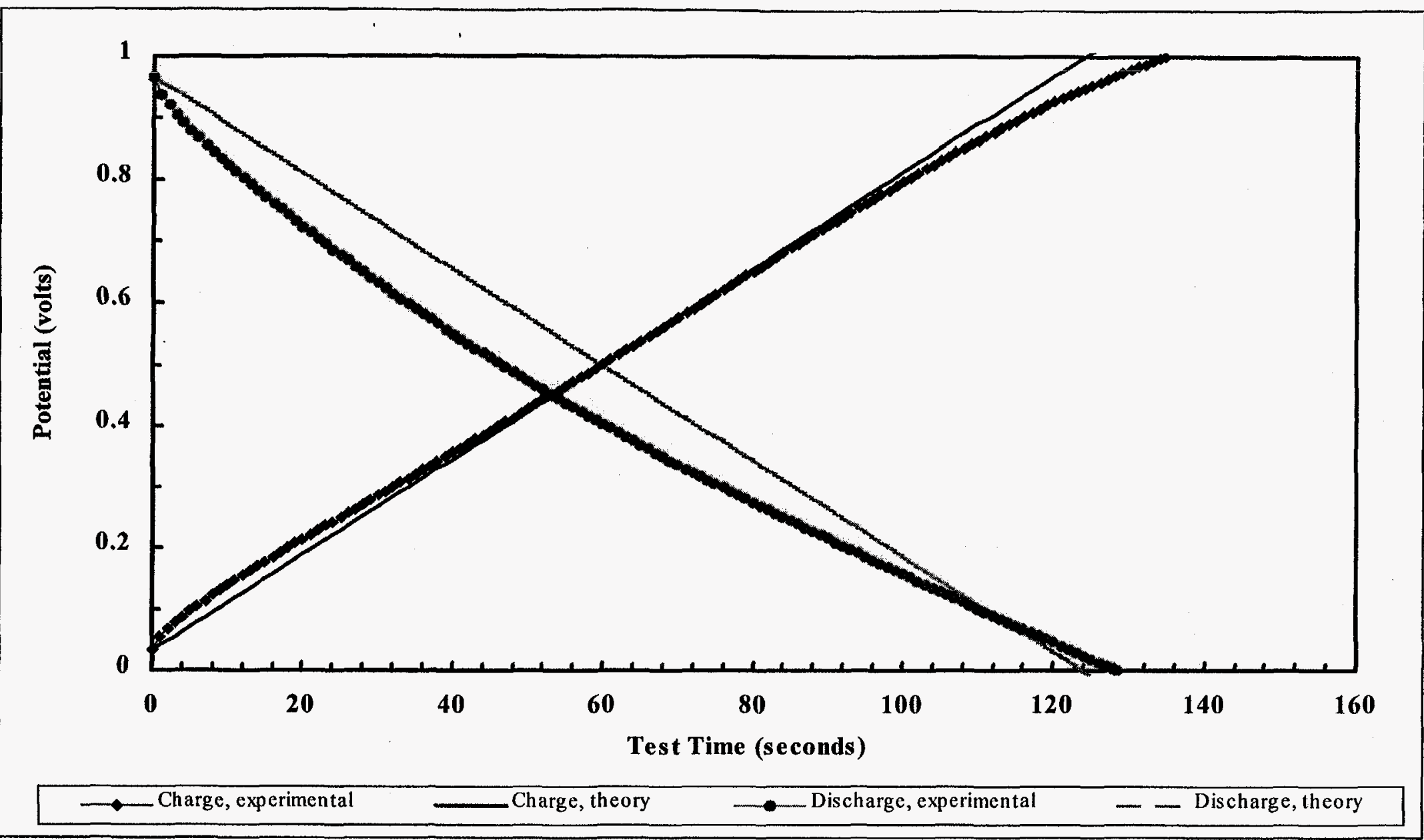

Figure A-18. Experimental and calculated (using the theoretical ideal-capacitor model) of the charge and discharge potential as a function of test time for a $0.1 \mathrm{~A}$ constant-current charge from $0 \mathrm{~V}$ to $1 \mathrm{~V}$, and a $0.1 \mathrm{~A}$ constant-current discharge from $1 \mathrm{~V}$ to $0 \mathrm{~V}$ for capacitor \#P20-032. 


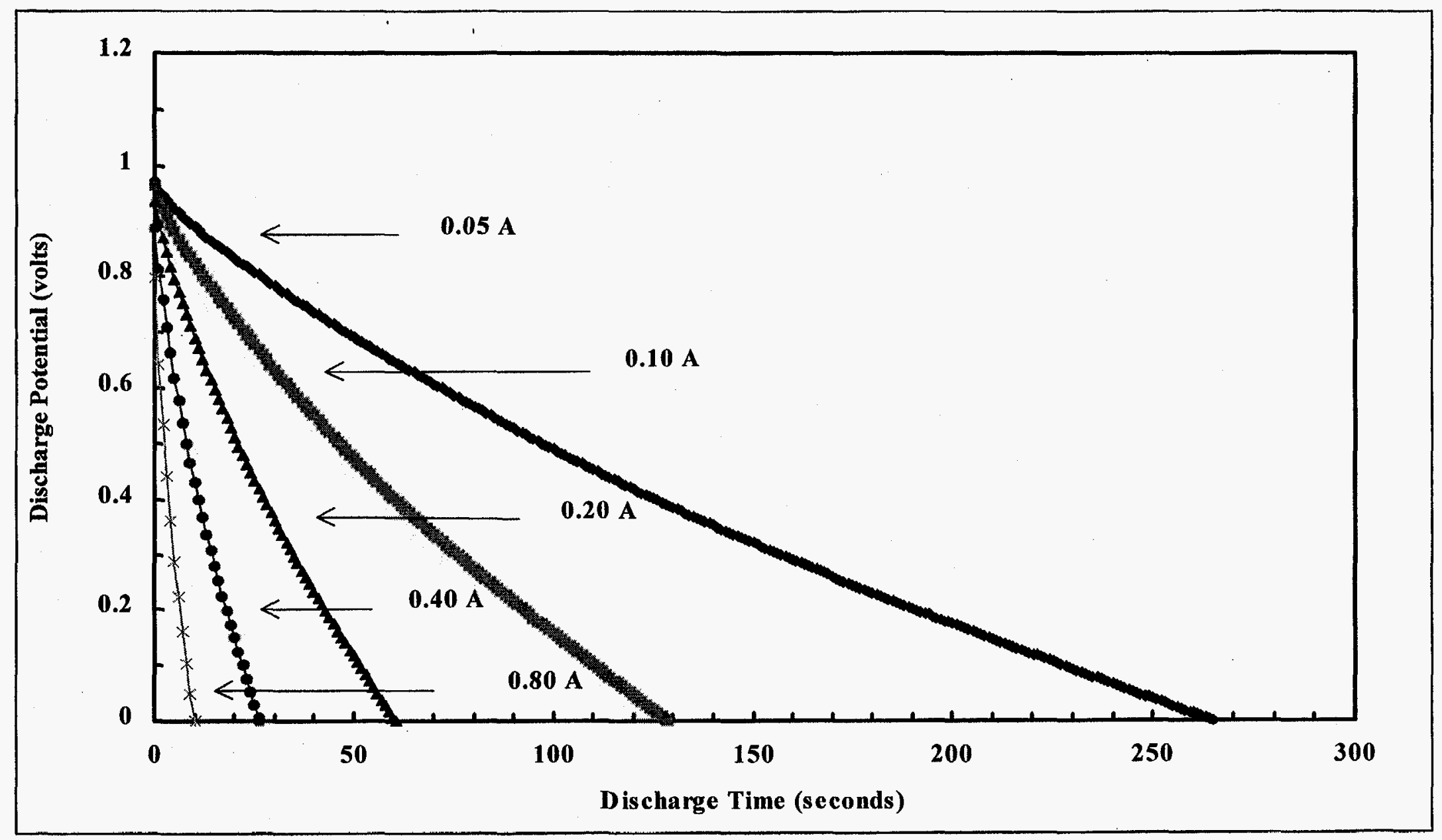

Figure A-19. Capacitor discharge potential for capacitor \#P20-032 for $1 \mathrm{~V}$ to $0 \mathrm{~V}$ as a function of discharge time for constantcurrent tests that used $0.05 \mathrm{~A}, 0.10 \mathrm{~A}, 0.20 \mathrm{~A}, 0.40 \mathrm{~A}$, and $0.80 \mathrm{~A}$ constant-current discharges. All tests used a $0.1 \mathrm{~A}$ constantcurrent charge. 


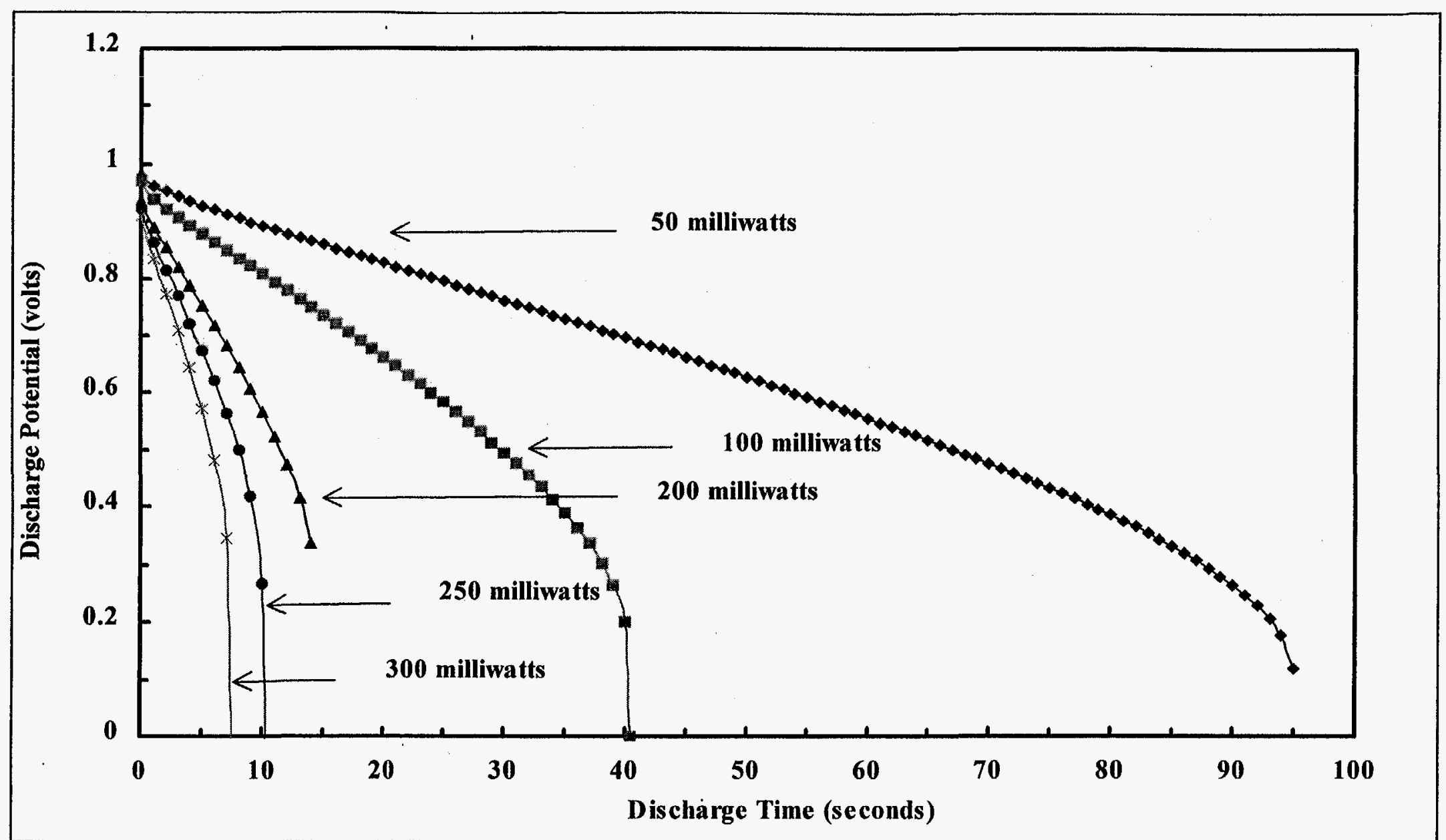

Figure A-20. Discharge as a function of discharge time for constant-power discharge tests at 50 milliwatts, 100 milliwatts, 200 milliwatts, 250 milliwatts, and 300 milliwatts for capacitor \#P20-032. 


$$
M
$$




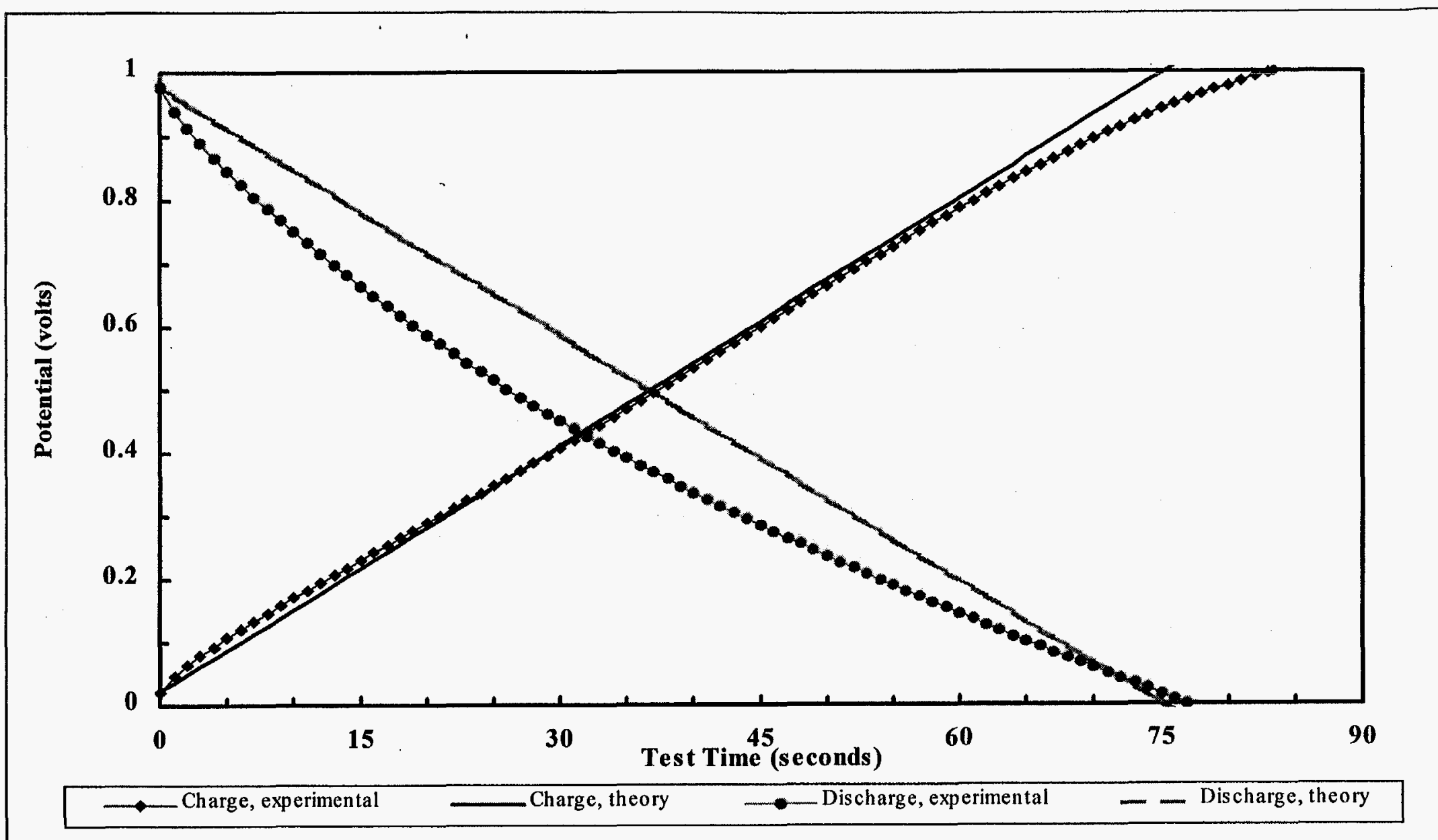

Figure A-22. Experimental and calculated (using the theoretical ideal-capacitor model) of the charge and discharge potential as a function of test time for a $0.1 \mathrm{~A}$ constant-current charge from $0 \mathrm{~V}$ to $1 \mathrm{~V}$, and a $0.1 \mathrm{~A}$ constant-current discharge from $1 \mathrm{~V}$ to $0 \mathrm{~V}$ for capacitor \#P20-033. 


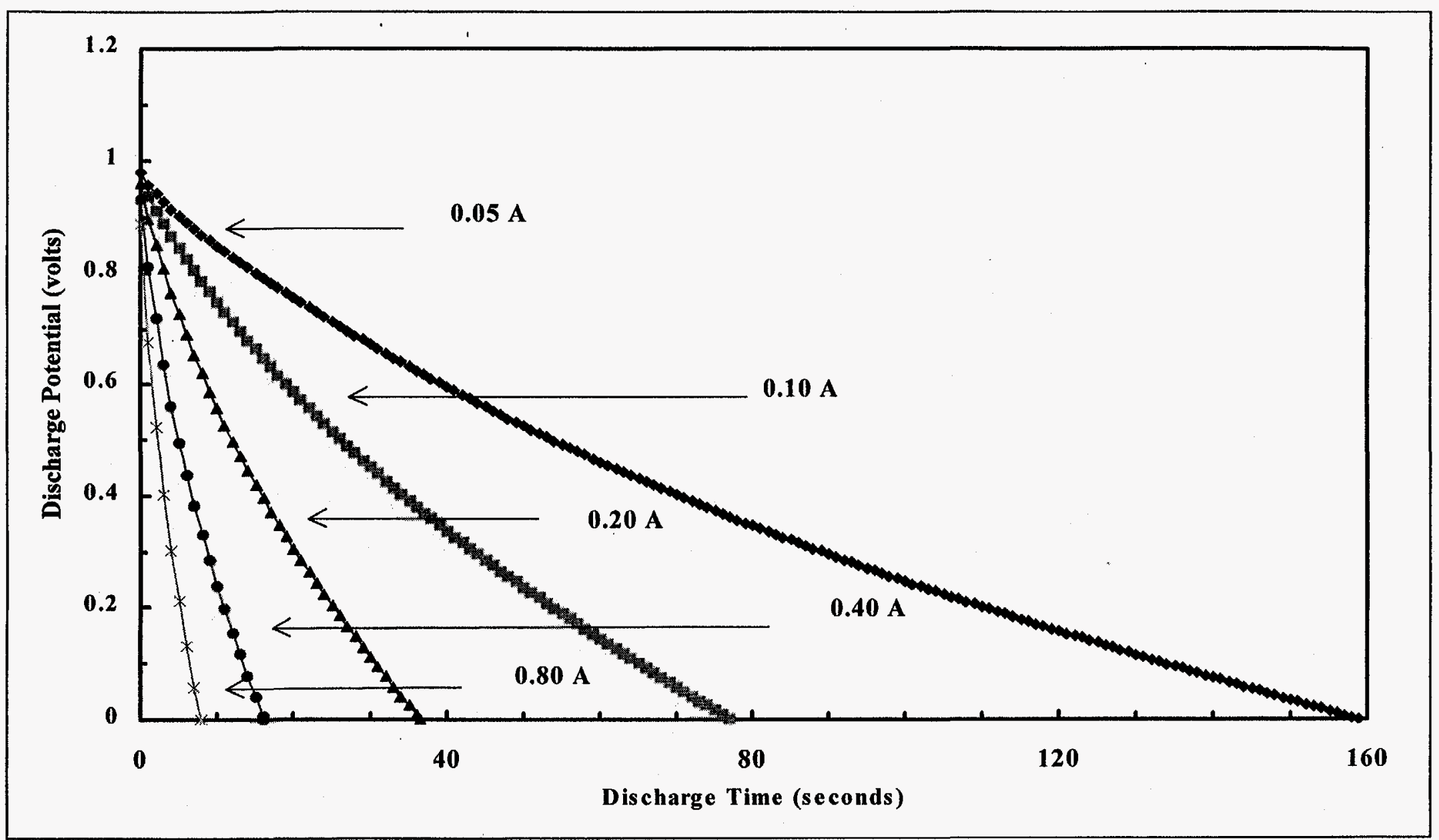

Figure A-23. Capacitor discharge potential for capacitor \#P20-033 for $1 \mathrm{~V}$ to $0 \mathrm{~V}$ as a function of discharge time for constantcurrent tests which used $0.05 \mathrm{~A}, 0.10 \mathrm{~A}, 0.20 \mathrm{~A}, 0.40 \mathrm{~A}$, and $0.80 \mathrm{~A}$ constant-current discharges. All tests used a $0.1 \mathrm{~A}$ constantcurrent charge. 


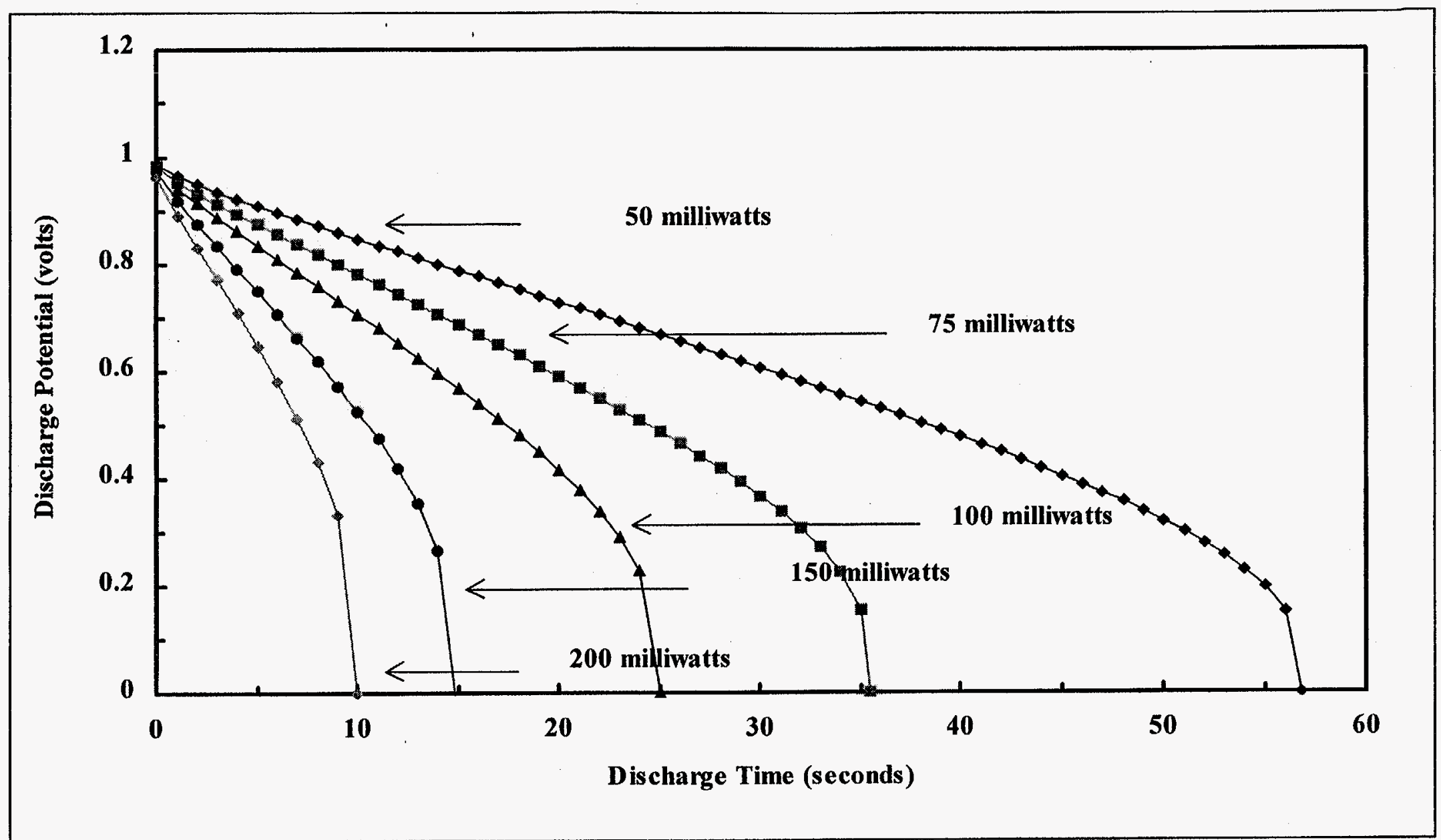

Figure A-24. Discharge potential as a function of discharge time for constant-power discharge tests at 50 milliwatts, 75 milliwatts, 100 milliwatts, 150 milliwatts, and 200 milliwatts for capacitor \#P20-033. 